\title{
Article \\ Temperature Dependence of Density and Viscosity of Biobutanol-Gasoline Blends
}

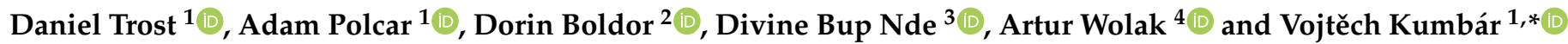 \\ 1 Department of Technology and Automobile Transport, Mendel University in Brno, Zemědělská 1665/1, \\ 61300 Brno, Czech Republic; xtrost@mendelu.cz (D.T.); adam.polcar@mendelu.cz (A.P.) \\ 2 Department of Biological and Agricultural Engineering, Louisiana State University Agricultural Center, \\ 149 E. B. Doran Building, Baton Rouge, LA 70803-4505, USA; DBoldor@agcenter.lsu.edu \\ 3 College of Technology, University of Bamenda, Bamenda, P.O. Box 39, Bambili, Cameroon; bupdiv@yahoo.fr \\ 4 Department of Quality and Safety of Industrial Products, Cracow University of Economics, Rakowicka 27, \\ 31-510 Kraków, Poland; artur.wolak@uek.krakow.pl \\ * Correspondence: vojtech.kumbar@mendelu.cz; Tel.: +420-545132128
}

check for updates

Citation: Trost, D.; Polcar, A.; Boldor, D.; Nde, D.B.; Wolak, A.; Kumbár, V. Temperature Dependence of Density and Viscosity of Biobutanol-Gasoline Blends. Appl. Sci. 2021, 11, 3172. https://doi.org/10.3390/app11073172

Received: 15 March 2021

Accepted: 30 March 2021

Published: 2 April 2021

Publisher's Note: MDPI stays neutra with regard to jurisdictional claims in published maps and institutional affiliations.

Copyright: (c) 2021 by the authors. Licensee MDPI, Basel, Switzerland. This article is an open access article distributed under the terms and conditions of the Creative Commons Attribution (CC BY) license (https:// creativecommons.org/licenses/by/ $4.0 /)$
Featured Application: The results are applicable in industrial practice. The models with the coefficients could be used to set a car control unit, which would be able to evaluate the exact amount of fuel needed for injection into the combustion chamber according to the current concentration of the biobutanol in the gasoline and current temperature of the fuel, because, as this paper stated, these can affect the fuel volumetric mass density and the dynamic/kinematic viscosity.

Abstract: Butanol seems to be an eligible fuel for compensating for the increasing fuel consumption. Biobutanol could be produced from local sources in the place of use. Its properties show similar results to gasoline, so biobutanol could be added as a biocomponent into fuels. Important properties, in the case of blending biobutanol into gasoline, are its fluid properties and their dependence on the temperature. Therefore, in this paper, the volumetric mass density and viscosity of the selected ratios between biobutanol and gasoline $(0,5,10,85,100 \mathrm{vol} . \%)$ were tested over the temperature range from $-10{ }^{\circ} \mathrm{C}$ up to $40{ }^{\circ} \mathrm{C}$. Gasolines with a 95 Research Octane Number (RON 95) and with a 98 Research Octane Number (RON 98) were used. It was observed that as the temperature increased, the viscosity and volumetric mass density of the samples decreased nonlinearly. Four mathematical models were used for modelling the viscosity. The accuracy of models was evaluated and compared according to the coefficient of determination $R^{2}$ and sum of squared estimate of errors (SSE). The results show that blends with 5 vol. $\%$ and 10 vol. $\%$ of biobutanol promise very similar fluid properties to pure gasoline. In contrast, a blend with 85 vol.\% of biobutanol shows different fluid properties from gasoline, especially in negative temperatures, a lot. For practical applications, mathematical polynomial multivariate models were created. Using these models, three-dimensional graphs were constructed.

Keywords: biobutanol; gasoline; viscosity; density; low temperature; mathematical model

\section{Introduction}

In the current consumer society, characterised by an increase in the population, a corresponding increase in the consumption of resources, especially fuels, are required. Unless significant changes are made in the energy sector, fuel needs could increase up to $48 \%$ from 2012 to 2040 [1]. Furthermore, it is assumed that by 2030 fossil fuels will become the most expensive energy source. With consideration to the depleting oil resources, market volatility, greenhouse gas (GHG) emissions and required mitigation strategies, and the environmentally unfriendly character of processing crude oils, it would be appropriate to develop other ecological and sustainable sources [2]. Another successful approach is the in situ gasoline upgrade into strong anti-knocking alcohol mixtures [3]. Therefore, many studies have been concentrated on this topic nowadays in order to find suitable renewable sources that can replace or supplement fossil fuels, e.g., [4-6]. 
A promising solution seems to be the processing of biofuels. Two of the main advantages of using biofuels is its good availability and the abundance of local raw materials for production-directly at the place of consumption. Biofuels can replace petroleum fuels mainly in the transportation sector and, in many cases, without the replacement of the existing powertrain design. Of the various biofuels, biobutanol (especially produced from lignocellulosic raw materials [7]) seems to be one of the most appealing because biobutanol has attractive properties such as a higher heating value/specific energy, cetane number, hydrophobicity, and low vapour pressure [8,9]. Furthermore, it is less corrosive and volatile [10]. Currently, in the US and Europe, biofuels are blended with commonly used fuels, referred to as E5, E7, and E10 per Directive 2008/50/EC in Europe. The former and latter express the type of fuel used as the bio-component (bioethanol or fatty acid methyl ester, respectively) as well as the quantity of the biofuel $(5,7$, or $10 \mathrm{vol} . \%$, respectively) that have been incorporated into the fossil fuel. Biobutanol can be produced similarly to bioethanol by fermentation of the directly fermentable simple sugars, called the $\mathrm{ABE}$ (Acetone-Butanol-Ethanol) process under the action of the microorganism (Clostridium acetobutylicum) [11]. Starch crops (cereals, maize, and potatoes) and molasses from the sugar cane or sugar beet are the traditional raw materials used to produce biobutanol [12,13]. On the other hand, microalgae strains are also gaining attention as an advanced energy feedstock for biofuel production $[14,15]$. Due to the similar properties to common use fuels, it is possible to add larger amounts of biobutanol into a fuel, which would result in a bigger fossil fuel savings. Although many science papers have been published about biobutanol as a promising biofuel, (e.g., [16-18]) only a couple of them have investigated the temperature effect on the rheological properties (kinematic and dynamic viscosity) of the fuel, and only for bioethanol [19]. The temperature dependent properties are crucial for understanding the performance of the fuel and, subsequently, the engine over a given period of time [20,21].

Therefore, the objective of this work is to survey the fluid behaviour of biobutanolgasoline blends (volumetric mass density, dynamic viscosity, kinematic viscosity) through the whole year's temperature range that normally occur for most European countries (from $-10^{\circ} \mathrm{C}$ up to $40^{\circ} \mathrm{C}$ ) and the subsequent modelling of this behaviour.

\section{Materials and Methods}

\subsection{Material}

In this study, automobile gasolines with a 95 Research Octane Number (RON 95) and with a 98 Research Octane Number (RON 98), both without a biocomponent (Čepro, Czech Republic) and biobutanol (Penta, Czech Republic) were used. Five samples with various volume concentrations of gasoline and biobutanol were prepared, see Table 1. The sample identification is according to the volume ratio of the biobutanol in the whole blend (e.g., B10 contains 10 vol. \% of biobutanol and 90 vol. $\%$ of gasoline).

Table 1. Composition of samples.

\begin{tabular}{ccc}
\hline Sample & Volume of Biobutanol & Volume of Gasoline \\
\hline B0 & $0 \%$ & $100 \%$ \\
B5 & $5 \%$ & $95 \%$ \\
B10 & $10 \%$ & $90 \%$ \\
B85 & $85 \%$ & $15 \%$ \\
B100 & $100 \%$ & $0 \%$ \\
\hline
\end{tabular}

The typical physical and chemical properties of the fuels (gasoline, bioethanol, and biobutanol) are shown in Table 2.

\subsection{Volumetric Mass Density Measuring}

The values of the volumetric mass density of the biobutanol-gasoline samples were measured by a digital Densito 30 PX densitometer (Mettler Toledo, Columbus, OH, USA) 
operating on an oscillating tube principle. All the samples were measured in temperature range from -10 to $40^{\circ} \mathrm{C}(\sim 263-313 \mathrm{~K})$. The ASTM D4052 standard was followed throughout the whole experiment.

Table 2. Comparison of selected properties of fuels [22,23].

\begin{tabular}{|c|c|c|c|c|}
\hline Property & Unit & Gasoline & Bioethanol & Biobutanol \\
\hline Chemical formula & & $\mathrm{C}_{4}$ to $\mathrm{C}_{12}$ & $\mathrm{C}_{2} \mathrm{H}_{5} \mathrm{OH}$ & $\mathrm{C}_{4} \mathrm{H}_{9} \mathrm{OH}$ \\
\hline Molecular mass & $\mathrm{kg} \cdot \mathrm{mol}^{-1}$ & 109 & 46 & 74 \\
\hline Volumetric mass density $\left(15^{\circ} \mathrm{C}\right)$ & $\mathrm{kg} \cdot \mathrm{m}^{-3}$ & $720-775$ & 789 & 814 \\
\hline Calorific value & $\mathrm{MJ} \cdot \mathrm{kg}^{-1}$ & 43.3 & 29 & 33 \\
\hline Heat of vaporization & $\mathrm{kJ} \cdot \mathrm{kg}^{-1}$ & 349 & 918 & 583 \\
\hline Octane number ROM & - & $91-99$ & 107 & 96 \\
\hline Boiling point & ${ }^{\circ} \mathrm{C}$ & $27-225$ & 78 & 104 \\
\hline Flash point & ${ }^{\circ} \mathrm{C}$ & -45 & 13 & 35 \\
\hline Auto ignition Temp. & ${ }^{\circ} \mathrm{C}$ & 258 & 420 & 415 \\
\hline Stoichiometric AFR & - & 14.7 & 9.01 & 11.12 \\
\hline
\end{tabular}

\subsection{Viscosity Measuring}

To determine the dynamic viscosity, a DV2T rotary viscometer (Brookfield, Middleboro, MA, USA) with standard spindle 18 (according the Brookfield) was used. The shear strain rate was set to a constant $200 \mathrm{~s}^{-1}$. During the experiment, the similar procedure that was already used for gasoline-bioethanol and diesel-biobutanol blends in the papers $[19,24,25]$ was followed. All the samples were measured in a temperature range from -10 to $40{ }^{\circ} \mathrm{C}(\sim 263-313 \mathrm{~K})$. Each sample was cooled down to $-10{ }^{\circ} \mathrm{C}$ and gradually heated by $5{ }^{\circ} \mathrm{C}$ steps and after $2 \mathrm{~min}$ of stabilising the temperature, the viscosity was measured. A closed measuring cuvette was used to prevent evaporation of the sample during the measurement.

The kinematic viscosity was calculated from the dynamic viscosity and volumetric mass density using the equation:

$$
v=\frac{\eta}{\rho}
$$

where $v$ is the kinematic viscosity, $\eta$ is the dynamic viscosity, and $\rho$ is the volumetric mass density.

\subsection{Mathematical Models for the Density, Dynamic, and Kinematic Viscosity}

In this paper, four mathematical models were used for the temperature dependence of the volumetric mass density and both viscosities. These models are used for nonlinear (frequently exponential) dependences, which is also observed in the temperature dependence of the volumetric mass density and the viscosity of the fuels.

Some of models below were used also in papers [26-30]. The details and formulas of the used mathematical models are shown below.

Exponential model:

$$
\begin{gathered}
\eta=\eta_{0} \cdot e^{b \cdot T} \text { for dynamic viscosity } \\
\eta=\eta_{0} \cdot e^{b \cdot T} \text { for dynamic viscosity } \\
\rho=\rho_{0} \cdot e^{b \cdot T} \text { for volumetric mass density }
\end{gathered}
$$

Arrhenius model:

$$
\begin{aligned}
& \eta=\eta_{0} \cdot e^{\frac{E_{a}}{R \cdot T}} \text { for dynamic visvosity } \\
& v=v_{0} \cdot e^{\frac{E_{a}}{R \cdot T}} \text { for kinematic viscosity }
\end{aligned}
$$

Newton model:

$$
\eta=\eta_{0} \cdot e^{\frac{b}{T}} \text { for dynamic viscosity }
$$




$$
v=v_{0} \cdot e^{\frac{b}{T}} \text { for kinematic viscosity }
$$

Vogel model:

$$
\begin{aligned}
& \eta=\eta_{0} \cdot e^{\frac{b}{c+T}} \text { for dynamic viscosity } \\
& v=v_{0} \cdot e^{\frac{b}{c+T}} \text { for kinematic viscosity }
\end{aligned}
$$

where $\eta$ is the dynamic viscosity, $\eta_{0}$ is the reference value of the dynamic viscosity, $v$ is the kinematic viscosity, $v_{0}$ is the reference value of the kinematic viscosity, $\rho$ is the volumetric mass density, $\rho_{0}$ is the reference value of the volumetric mass density, $T$ is the absolute temperature, $R$ is the Universal gas constant, $E_{a}$ is the Arrhenius activation energy, and $b$ and $c$ are coefficients.

Furthermore, mathematical polynomial multivariate models were created. These models describe the behaviour of the volumetric mass density or kinematic viscosity of the biobutanol-gasoline blends depending on their temperature and concentration. The models were created for both the RON 95 and RON 98 gasolines. The equations of the multivariate models are given below based on polynomial functions.

The volumetric mass density:

$$
\rho(T, C)=x_{0}+x_{1} \cdot T+x_{2} \cdot C+x_{3} \cdot T^{2}+x_{4} \cdot T \cdot C
$$

The kinematic viscosity:

$$
v(T, C)=y_{0}+y_{1} \cdot T+y_{2} \cdot C+y_{3} \cdot T^{2}+y_{4} \cdot T \cdot C .
$$

In Equations (11) and (12), $\rho$ is the volumetric mass density, $v$ is the kinematic viscosity, $T$ is the absolute temperature, $C$ is the concentration, and $x_{i}, y_{i}$ are coefficients.

\subsection{Statistical Data Processing}

All the measurements were repeated five times for volumetric mass density and 20 times for viscosity to obtain a higher accuracy and relevance of the results, and the values in the tables are displayed as the mean value including the standard deviation.

The experimental data were processed by Matlab ${ }^{\circledR}$ and Statistica ${ }^{\circledR}$. To determine a statistically significant difference between the measured values of the volumetric mass density, dynamic viscosity and kinematic viscosity at the selected temperatures at the individual gasoline (RON 95, RON 98) and biobutanol concentrations, an ANOVA (analysis of variance) test was performed followed by multiple comparisons using Tukey's HSD (honestly significant difference) test (at the significance level of $p<0.05$ ).

The normality and homogeneity of the data were evaluated according to a critique of the regression triplet data, which examines the quality of the data for the proposed model. The evaluation was performed by means of graphical (using rankit Q-Q graphs of residues and index graphs) and numerical statistical analysis of residues.

\section{Results and Discussion}

The following section comprehensively shows the values obtained during the experiments.

\subsection{Volumetric Mass Density}

Tables A1 and A2 (in Appendix A) shows the mean values of the volumetric mass density of the biobutanol-gasoline blends at the selected temperature range and concentration.

It can be seen that volumetric mass density of the blends decreases with an increasing temperature. Furthermore, the blends with a higher biobutanol content reach a higher volumetric mass density value and the RON 98 gasoline also has a higher volumetric mass density value than the RON 95 gasoline, similar to the bioethanol and gasoline blends $[19,25,31]$. 


\subsection{Dynamic Viscosity}

Tables A3 and A4 show the mean values of the dynamic viscosity of the biobutanolgasoline blends at the selected temperature range and concentration.

It is evident that the dynamic viscosity of the blends decreases with an increasing temperature. Furthermore, the blends with a higher concentration of biobutanol reach a higher dynamic viscosity value and the RON 98 gasoline also has a lower dynamic viscosity value than the RON 95 gasoline, similar to the viscosity values of the bioethanol-gasoline blends [18,32].

\subsection{Kinematic Viscosity}

The mean values of the kinematic viscosity of the biobutanol-gasoline blends for the selected temperature range and concentrations are shown in Tables A5 and A6. The tables also show the results of the ANOVA test with respect to the multiple comparisons using Tukey's HSD test in the similar indices (a, b, c, etc.). The same indices indicate that no statistically significant difference was demonstrated between the respective kinematic viscosity at the significance level of $p=0.95$.

From Tables A5 and A6, it can be seen that the kinematic viscosity values of the biobutanol-gasoline blends decrease with an increasing temperature. Also, the blends with a higher biobutanol content have higher kinematic viscosity values, and the RON 98 gasoline also has lower kinematic viscosity values than the RON 95 gasoline, similar to the bioethanol-gasoline blends [25]. The dependence of the kinematic viscosity on the concentration of the biocomponent in the fuel was also observed and described $[8,33]$.

\subsection{Mathematical Models}

Finally, the most important part of this paper is devoted to the mathematical modelling of the volumetric mass density and viscosity behaviour of the biobutanol-gasoline blends. This part mainly contains tables with the coefficients of used mathematical models which are listed in Section 2.4. The obtained coefficients of the models are valid for the thermodynamic temperatures with Kelvin units.

The mentioned coefficients, especially the coefficient of determination $R^{2}$ and sum of squared estimate of errors (SSE), express the degree of accuracy and suitability of using these mathematical models to model the dependence of the volumetric mass density and both viscosities on the temperature of the biobutanol-gasoline blends. Some of the used temperature-viscosity models were described and also used in the papers, e.g., [26-28].

\subsubsection{Mathematical Model for Volumetric Mass Density}

The values of the coefficients for the exponential volumetric mass density model are shown in Table 3 . The reference value of the volumetric mass density $\rho_{0}$ numerically determines the increase in the volumetric mass density of the blends with an increasing biobutanol volume concentration. The values of coefficient $b$ are close to 0 , so the temperature impact on the volumetric mass density approaches a linear dependence. The minus operator for the coefficient $b$ means a decreasing trend in the exponential model, respectively, a decreasing volumetric mass density of the biobutanol-gasoline blends with an increasing temperature $[8,24,34]$. The above statement is graphically confirmed by Figures 1 and 2. The average value of the coefficient of determination $R^{2}$ for the exponential volumetric mass density model was 0.9676 , which indicates the high accuracy of the models. 
Table 3. Coefficients of exponential volumetric mass density model and statistical indicators $\left(R^{2}-\right.$ coefficient of determination, SSE—sum of squared estimate of errors).

\begin{tabular}{|c|c|c|c|c|}
\hline Exponential & $\rho_{0}\left(\mathrm{~kg} \cdot \mathrm{m}^{-3}\right)$ & $b\left(K^{-1}\right)$ & $R^{2}$ & SSE \\
\hline B0-95 & 842.7 & -0.0003653 & 0.9675 & 7.094 \\
\hline B5-95 & 918.5 & -0.0006602 & 0.9108 & 67.90 \\
\hline B10-95 & 939.7 & -0.0007296 & 0.9800 & 17.37 \\
\hline B85-95 & 1054 & -0.0009530 & 0.9793 & 33.96 \\
\hline B0-98 & 950.2 & -0.0007528 & 0.9705 & 27.75 \\
\hline B5-98 & 989.9 & -0.0008632 & 0.9720 & 35.31 \\
\hline B10-98 & 973.6 & -0.0007975 & 0.9710 & 31.33 \\
\hline B85-98 & 1057 & -0.0009501 & 0.9824 & 28.75 \\
\hline B100 & 1074 & -0.0009863 & 0.9745 & 45.80 \\
\hline
\end{tabular}

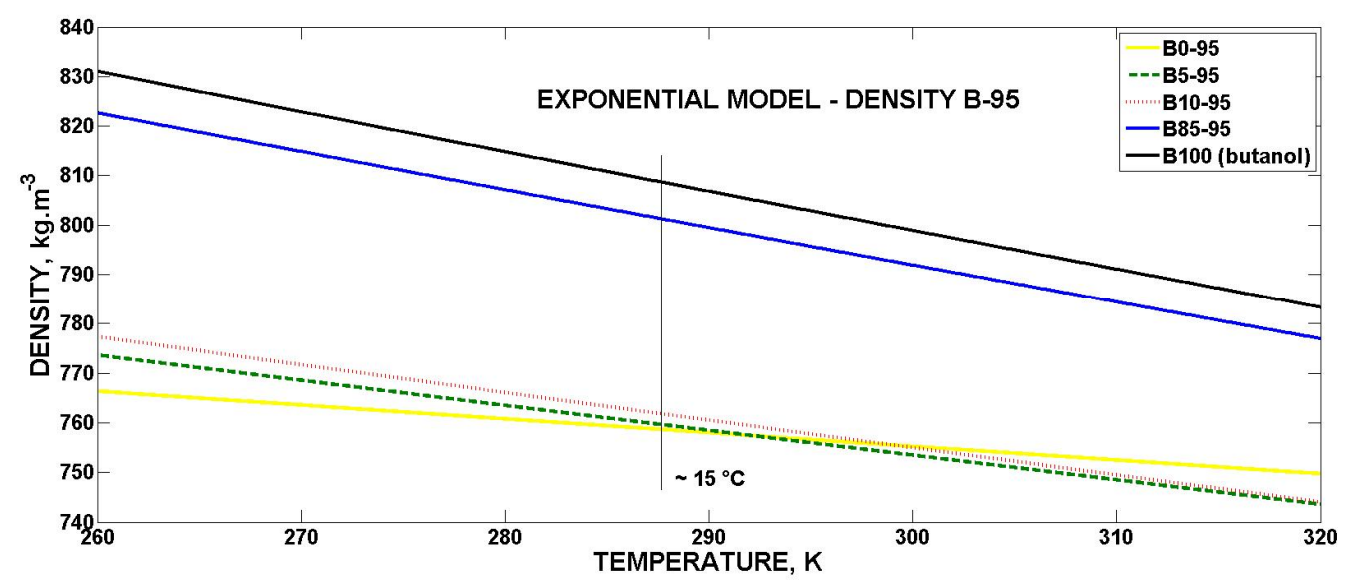

Figure 1. Exponential model for volumetric mass density of biobutanol-gasoline (RON 95) blends.

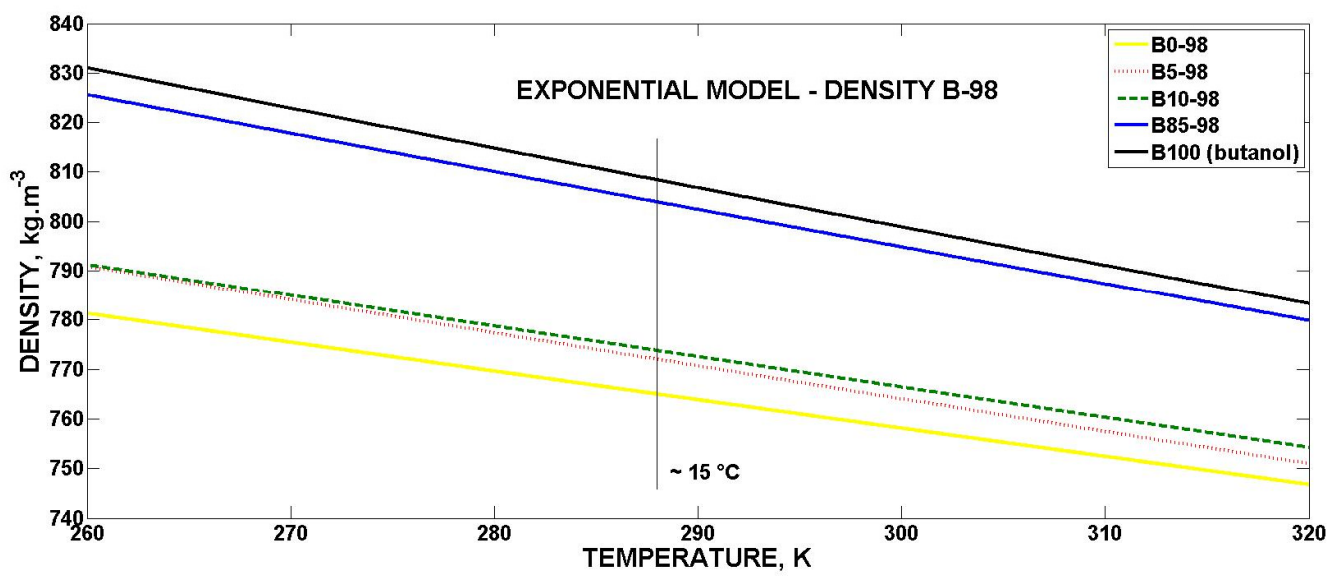

Figure 2. Exponential model for volumetric mass density of biobutanol-gasoline (RON 98) blends.

\subsubsection{Mathematical Models for Dynamic Viscosity}

The temperature dependence of the dynamic viscosity of the biobutanol-gasoline blends were modelled using four mathematical models, see Section 2.4 for more details. The coefficients of these models are shown in Tables 4-7. Thus, it was shown that with an increasing temperature, the dynamic viscosity of the biobutanol-gasoline blends decreases [32]. The difference between the Arrhenius model and Newtonian model is only in the use of the Universal gas constant $R$, so it holds that the coefficient $b$ (Newton model) multiplied by the Universal gas constant $R$ equals the Arrhenius activation energy $E_{a}$. However, knowledge of the Arrhenius activation energy $E_{a}$ of the biobutanol-gasoline 
blends is important and can be used for further calculations and applications [27-29]. In Table 7 (the coefficients of the Vogel model), several statistically insignificant coefficients can be seen, despite the Vogel model being the most accurate according to the highest average value of the coefficient of determination $R^{2}(0.9784)$ and average value of sum of squared estimate of errors SSE (0.0067). The Newton and Arrhenius models are in the next rows, which have an identical average value of $R^{2}(0.9234)$ and SSE (0.0514) and the exponential model has the lowest accuracy (but still very high), according to the results of the average value $R^{2}(0.8991)$ and SSE (0.0168).

Table 4. Coefficients of Exponential dynamic viscosity model and statistical indicators $\left(R^{2}-\right.$ coefficient of determination, SSE—sum of squared estimate of errors).

\begin{tabular}{|c|c|c|c|c|}
\hline Exponential & $\eta_{0}(\mathrm{mPa} \cdot \mathrm{s})$ & $b\left(\mathrm{~K}^{-1}\right)$ & $R^{2}$ & SSE \\
\hline B0-95 & 2.785 & -0.005277 & 0.8904 & 0.003453 \\
\hline B5-95 & 2.291 & -0.004474 & 0.8800 & 0.002957 \\
\hline B10-95 & 3.753 & -0.005958 & 0.8234 & 0.009255 \\
\hline B85-95 & 2.785 & -0.005277 & 0.8904 & 0.003453 \\
\hline B0-98 & 2.855 & -0.005526 & 0.9412 & 0.001755 \\
\hline B5-98 & 1.318 & -0.002481 & 0.8729 & 0.001026 \\
\hline B10-98 & 2.040 & -0.003918 & 0.7008 & 0.007626 \\
\hline B85-98 & 2926 & -0.024320 & 0.9974 & 0.033080 \\
\hline B100 & $1.141 \times 10^{4}$ & -0.028090 & 0.9971 & 0.088950 \\
\hline
\end{tabular}

Table 5. Coefficients of Arrhenius dynamic viscosity model and statistical indicators $\left(R^{2}\right.$ —coefficient of determination, SSE—sum of squared estimate of errors).

\begin{tabular}{ccccc}
\hline Arrhenius & $\boldsymbol{\eta}_{\mathbf{0}}(\mathbf{m P a} \cdot \mathbf{s})$ & $\boldsymbol{E}_{\boldsymbol{a}}\left(\mathbf{J} \cdot \mathbf{m o l}^{-\mathbf{1}}\right)$ & $\boldsymbol{R}^{\mathbf{2}}$ & $\mathrm{SSE}$ \\
\hline B0-95 & 0.1329 & 3634 & 0.9101 & 0.002831 \\
B5-95 & 0.1735 & 3085 & 0.8994 & 0.002481 \\
B10-95 & 0.1194 & 4134 & 0.8563 & 0.007531 \\
B85-95 & 0.003794 & $1.576 \times 10^{4}$ & 0.9996 & 0.005149 \\
B0-98 & 0.118700 & 3793 & 0.9566 & 0.001295 \\
B5-98 & 0.316800 & 1698 & 0.8742 & 0.001015 \\
B10-98 & 0.208800 & 2747 & 0.7397 & 0.006637 \\
B85-98 & 0.003084 & $1.615 \times 10^{4}$ & 0.9989 & 0.013940 \\
B100 & 0.001479 & $1.856 \times 10^{4}$ & 0.9997 & 0.010480 \\
\hline
\end{tabular}

Table 6. Coefficients of Newton dynamic viscosity model and statistical indicators $\left(R^{2}-\right.$ coefficient of determination, SSE—-sum of squared estimate of errors).

\begin{tabular}{ccccc}
\hline Newton & $\boldsymbol{\eta}_{\mathbf{0}}(\mathbf{m P a} \cdot \mathbf{s})$ & $\left.\boldsymbol{b} \mathbf{K}^{-\mathbf{1}}\right)$ & $\boldsymbol{R}^{\mathbf{2}}$ & SSE \\
\hline B0-95 & 0.132900 & 437.1 & 0.9101 & 0.002831 \\
B5-95 & 0.173500 & 371 & 0.8994 & 0.002481 \\
B10-95 & 0.119400 & 497.3 & 0.8563 & 0.007531 \\
B85-95 & 0.003794 & 1896 & 0.9996 & 0.005149 \\
B0-98 & 0.118700 & 456.2 & 0.9566 & 0.001295 \\
B5-98 & 0.316800 & 204.3 & 0.8742 & 0.001015 \\
B10-98 & 0.208800 & 330.4 & 0.7397 & 0.006637 \\
B85-98 & 0.003084 & 1942 & 0.9989 & 0.013940 \\
B100 & 0.001479 & 2233 & 0.9997 & 0.010480 \\
\hline
\end{tabular}

\subsubsection{Mathematical Models for Kinematic Viscosity}

For practical use, modelling the temperature dependence of the kinematic viscosity of the biobutanol-gasoline blends is the most suitable, because the kinematic viscosity contains information about the values of both the dynamic viscosity and the volumetric mass density of the blends [35]. Therefore, in the industrial and petrochemical fields, this viscosity is preferred, especially for temperature-dependent fluids. 
Table 7. Coefficients of Vogel dynamic viscosity model and statistical indicators $\left(R^{2}\right.$-coefficient of determination, SSE—sum of squared estimate of errors).

\begin{tabular}{cccccc}
\hline Vogel & $\boldsymbol{\eta}_{\mathbf{0}}(\mathbf{m P a} \cdot \mathbf{s})$ & $\boldsymbol{b}(\mathbf{K})$ & $\boldsymbol{c}(\mathbf{K})$ & $\boldsymbol{R}^{\mathbf{2}}$ & SSE \\
\hline B0-95 & 0.47170000 & $12.59 *$ & -233.8 & 0.9572 & 0.0013480 \\
B5-95 & 0.51300000 & $9.758^{*}$ & -235.9 & 0.9493 & 0.0012490 \\
B10-95 & 0.54120000 & 8.194 & -244.4 & 0.9700 & 0.0015740 \\
B85-95 & $0.0079680 *$ & 1500 & $-31.16^{*}$ & 0.9996 & 0.0047340 \\
B0-98 & 0.40190000 & $25.06^{*}$ & -216.5 & 0.9782 & 0.0006507 \\
B5-98 & $0.0008957^{*}$ & $2703^{*}$ & $50.67 *$ & 0.9989 & 0.0133100 \\
B10-98 & 0.58500000 & $3.513^{*}$ & -250.8 & 0.9321 & 0.0147100 \\
B85-98 & $0.0008959 *$ & $2703^{*}$ & $50.66^{*}$ & 0.9989 & 0.0133100 \\
B100 & $0.0037680 *$ & 1737 & $-33.16^{*}$ & 0.9997 & 0.0093950 \\
\hline
\end{tabular}

The temperature dependence of the kinematic viscosity of the biobutanol-gasoline blends were also modelled using four mathematical models (see Section 2.4). The coefficients of these models are shown in Tables 8-11. Again, it has been proven that with an increasing temperature, the kinematic viscosity of the gasolines (RON 95 and RON 98) and biobutanol nonlinearly decreases [36], which is confirmed by the coefficients of the mathematical models in Figures 3-5. In Table 11 (the coefficients of the Vogel model), several statistically insignificant coefficients can be seen, despite the Vogel model being the most accurate according to the highest average value of the coefficient of determination $R^{2}$ (0.9411) and average value of sum of squared estimate of errors SSE (0.0040) without SSE of B100. The Newton and Arrhenius models followed with an average $R^{2}$ value 0.8621 and SSE value 0.0353 , and the exponential model has the lowest accuracy (but still very high), according to the results of the average value $R^{2}(0.8440)$ and SSE $(0.0387)$.

Table 8. Coefficients of Exponential kinematic viscosity model and statistical indicators $\left(R^{2}-\right.$ coefficient of determination, SSE—sum of squared estimate of errors).

\begin{tabular}{ccccc}
\hline Exponential & $\boldsymbol{v}_{\mathbf{0}}\left(\mathbf{m m}^{\mathbf{2}} \cdot \mathbf{s}^{-\mathbf{1}}\right)$ & $\boldsymbol{b} \mathbf{( K}^{-\mathbf{1}} \mathbf{)}$ & $\boldsymbol{R}^{\mathbf{2}}$ & SSE \\
\hline B0-95 & 3.2970 & -0.004905 & 0.8745 & 0.006032 \\
B5-95 & 0.8766 & -0.003729 & 0.7472 & 0.008742 \\
B10-95 & 4.1030 & -0.005324 & 0.7760 & 0.017080 \\
B85-95 & 2465 & -0.022790 & 0.9961 & 0.072730 \\
B0-98 & 3.0930 & -0.004876 & 0.9157 & 0.003430 \\
B5-98 & 1.3070 & -0.001549 & 0.7127 & 0.001855 \\
B10-98 & 2.0960 & -0.003125 & 0.5800 & 0.013700 \\
B85-98 & 2356 & -0.021870 & 0.9950 & 0.131700 \\
B100 (butanol) & 8691 & -0.026090 & 0.9980 & 0.093450 \\
\hline
\end{tabular}

Table 9. Coefficients of Arrhenius kinematic viscosity model and statistical indicators $\left(R^{2}\right.$-coefficient of determination, SSE—sum of squared estimate of errors).

\begin{tabular}{ccccc}
\hline Arrhenius & $\boldsymbol{v}_{\mathbf{0}}\left(\mathbf{m m}^{\mathbf{2}} \cdot \mathbf{s}^{-\mathbf{1}}\right)$ & $\boldsymbol{E}_{\boldsymbol{a}} \mathbf{( J \cdot \mathbf { m o l } ^ { - \mathbf { 1 } } )}$ & $\boldsymbol{R}^{\mathbf{2}}$ & $\mathrm{SSE}$ \\
\hline B0-95 & 0.194500 & 3384 & 0.8962 & 0.004991 \\
B5-95 & 0.279800 & 2594 & 0.7751 & 0.007778 \\
B10-95 & 0.187100 & 3711 & 0.8129 & 0.014270 \\
B85-95 & 0.006053 & $1.518 \times 10^{4}$ & 0.9995 & 0.010040 \\
B0-98 & 0.186200 & 3356 & 0.9345 & 0.002662 \\
B5-98 & 0.534300 & 1070 & 0.7247 & 0.001777 \\
B10-98 & 0.337500 & 2211 & 0.6217 & 0.012340 \\
B85-98 & 0.009614 & $1.459 \times 10^{4}$ & 0.9991 & 0.022710 \\
B100 & 0.003469 & $1.725 \times 10^{4}$ & 0.9950 & 0.240900 \\
\hline
\end{tabular}


Table 10. Coefficients of Newton kinematic viscosity model and statistical indicators $\left(R^{2}\right.$-coefficient of determination, SSE—sum of squared estimate of errors).

\begin{tabular}{|c|c|c|c|c|}
\hline Newton & $v_{0}\left(\mathrm{~mm}^{2} \cdot \mathrm{s}^{-1}\right)$ & $b\left(K^{-1}\right)$ & $R^{2}$ & SSE \\
\hline B0-95 & 0.194500 & 407.1 & 0.8962 & 0.004991 \\
\hline B5-95 & 0.279800 & 371 & 0.7751 & 0.007778 \\
\hline B10-95 & 0.187100 & 446.3 & 0.8129 & 0.014270 \\
\hline B85-95 & 0.006053 & 1826 & 0.9995 & 0.010040 \\
\hline B0-98 & 0.186200 & 403.6 & 0.9345 & 0.002662 \\
\hline B5-98 & 0.534300 & 128.7 & 0.7247 & 0.001777 \\
\hline B10-98 & 0.337500 & 265.9 & 0.6217 & 0.012340 \\
\hline B85-98 & 0.009614 & 1755 & 0.9991 & 0.022710 \\
\hline B100 & 0.003469 & 2075 & 0.9950 & 0.240900 \\
\hline
\end{tabular}

Table 11. Coefficients of Vogel kinematic viscosity model and statistical indicators $\left(R^{2}\right.$-coefficient of determination, SSE—sum of squared estimate of errors).

\begin{tabular}{cccccc}
\hline Vogel & $\begin{array}{c}\boldsymbol{v}_{\mathbf{0}} \\
\left(\mathbf{m m}^{\mathbf{2}} \cdot \mathbf{s}^{-\mathbf{1})}\right.\end{array}$ & $\boldsymbol{b} \mathbf{( K )}$ & $\boldsymbol{c} \mathbf{( K )}$ & $\boldsymbol{R}^{\mathbf{2}}$ & SSE \\
\hline B0-95 & 0.644000 & $10.02 *$ & -237.2 & 0.9542 & 0.002200 \\
B5-95 & 0.736600 & $3.685 *$ & -249.3 & 0.9069 & 0.003220 \\
B10-95 & 0.740600 & 5.904 & -247.8 & 0.9618 & 0.002911 \\
B85-95 & $0.02609 *$ & 1093 & -63.79 & 0.9996 & 0.006728 \\
B0-98 & 0.571300 & $16.83 *$ & -224.7 & 0.9670 & 0.001343 \\
B5-98 & 0.799100 & $1.329 *$ & -250.8 & 0.7937 & 0.001332 \\
B10-98 & 0.782300 & $2.076^{*}$ & -254.3 & 0.8879 & 0.003658 \\
B85-98 & $0.0695 *$ & 814.2 & -89.9 & 0.9996 & 0.01064 \\
B100 & $1.511 \times 10^{*} *$ & $324 *$ & $7770 *$ & 0.9645 & 1.697 \\
\hline * ${ }^{*}$ coefficient is not statistically significant for confidence level $p<0.05$. & &
\end{tabular}

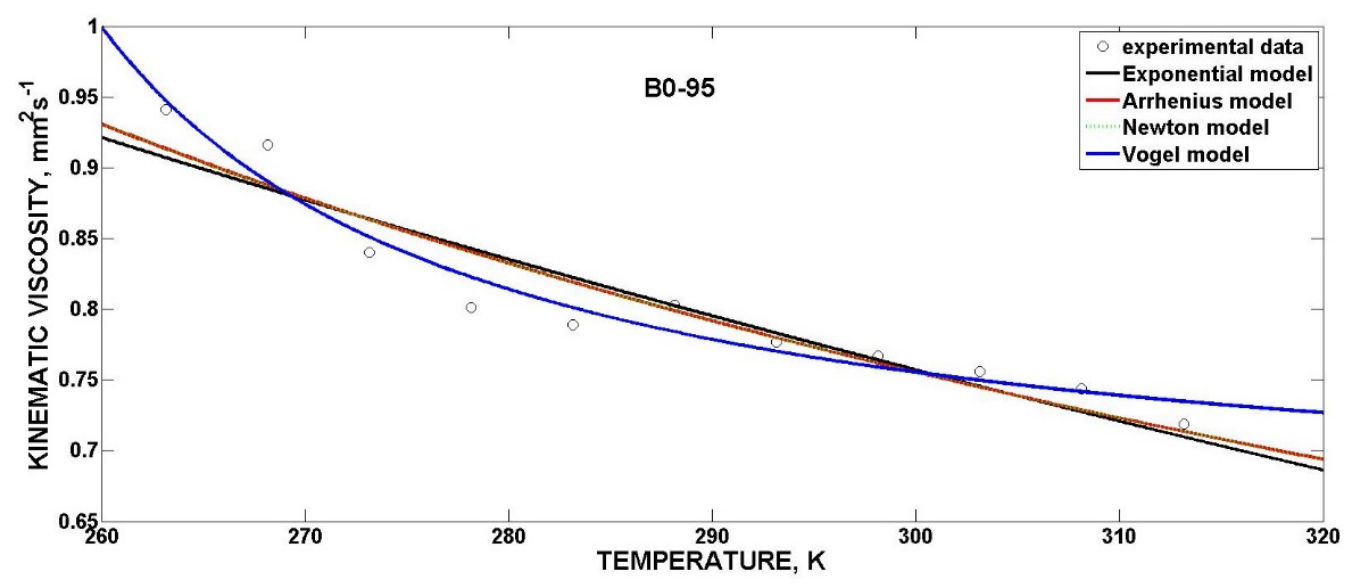

Figure 3. Mathematical models graph for kinematic viscosity of gasoline (RON 95). Experimental data are presented as the mean $(N=20)$ for selected temperatures.

In Figures 3-7, a relatively nonlinear decrease in the kinematic viscosity during the heating of gasolines, biobutanol, and their blends (especially when the Vogel model is used) can be seen. The lowest values in the kinematic viscosity were determined for B0 (pure gasoline) and the highest values in the kinematic viscosity were determined for B100 (pure biobutanol). The viscosity properties of the B5 and B10 blends approached that of the pure gasoline, which applies to both RON95 and RON 98. The viscosity behaviour of the B85 blend is close to the pure biobutanol viscosity behaviour. Similar results and conclusions were reached in $[4,21]$. 


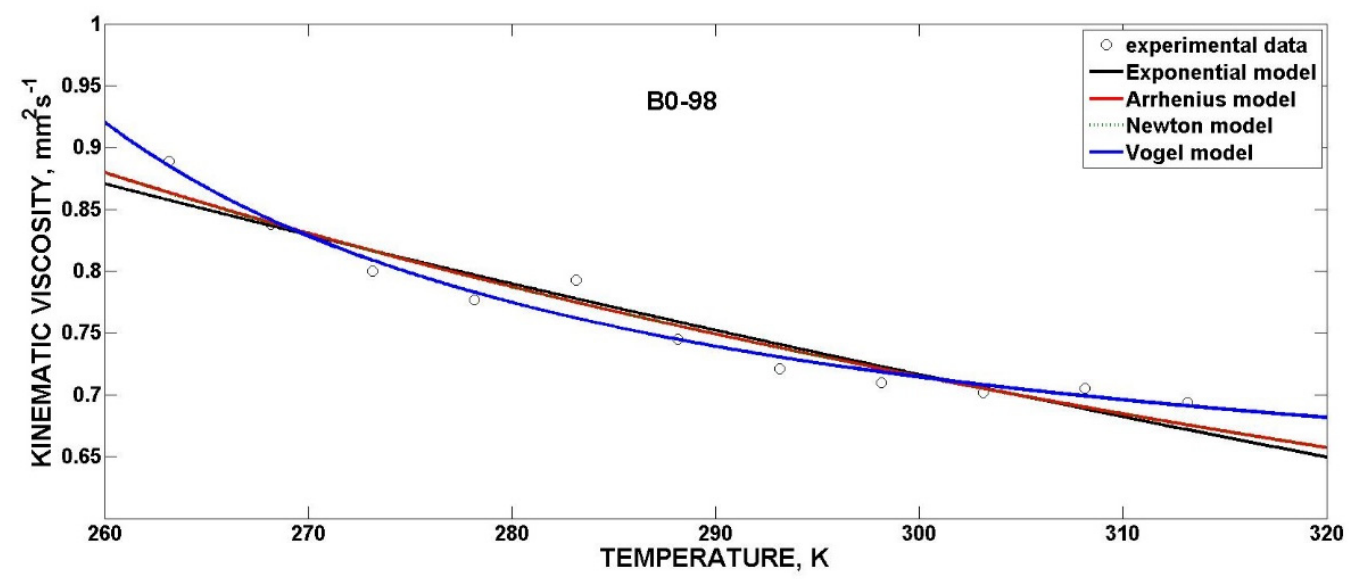

Figure 4. Mathematical models graph for kinematic viscosity of gasoline (RON 98). Experimental data are presented as the mean $(N=20)$ for selected temperatures.

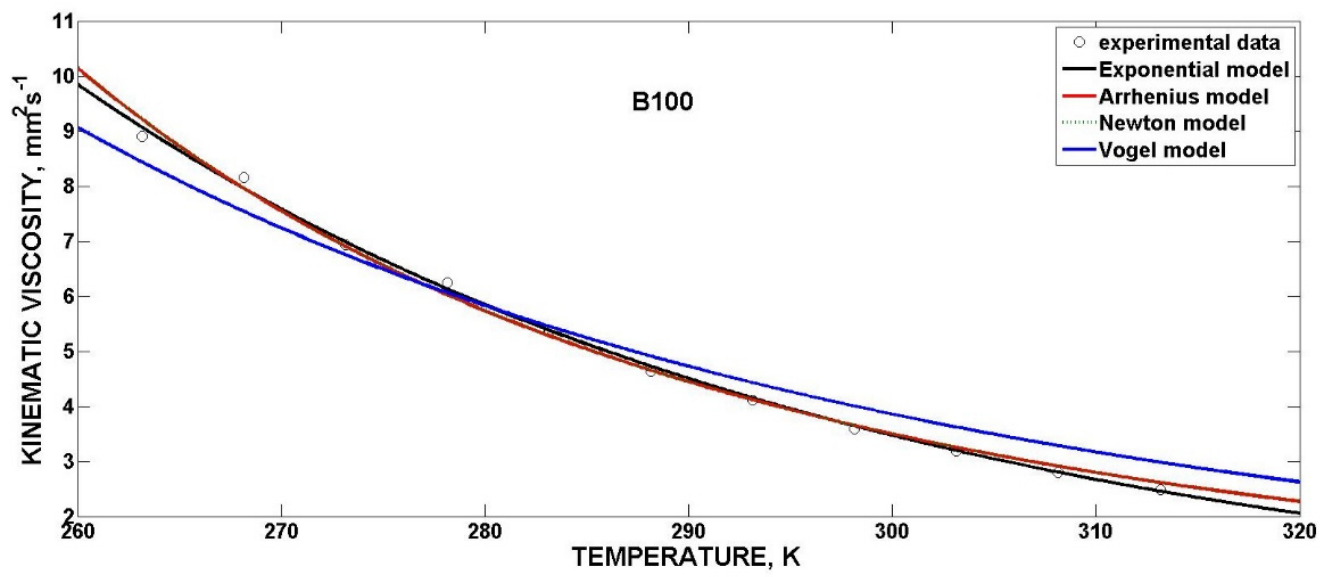

Figure 5. Mathematical models graph for kinematic viscosity of biobutanol (B100). Experimental data are presented as the mean $(N=20)$ for selected temperatures.

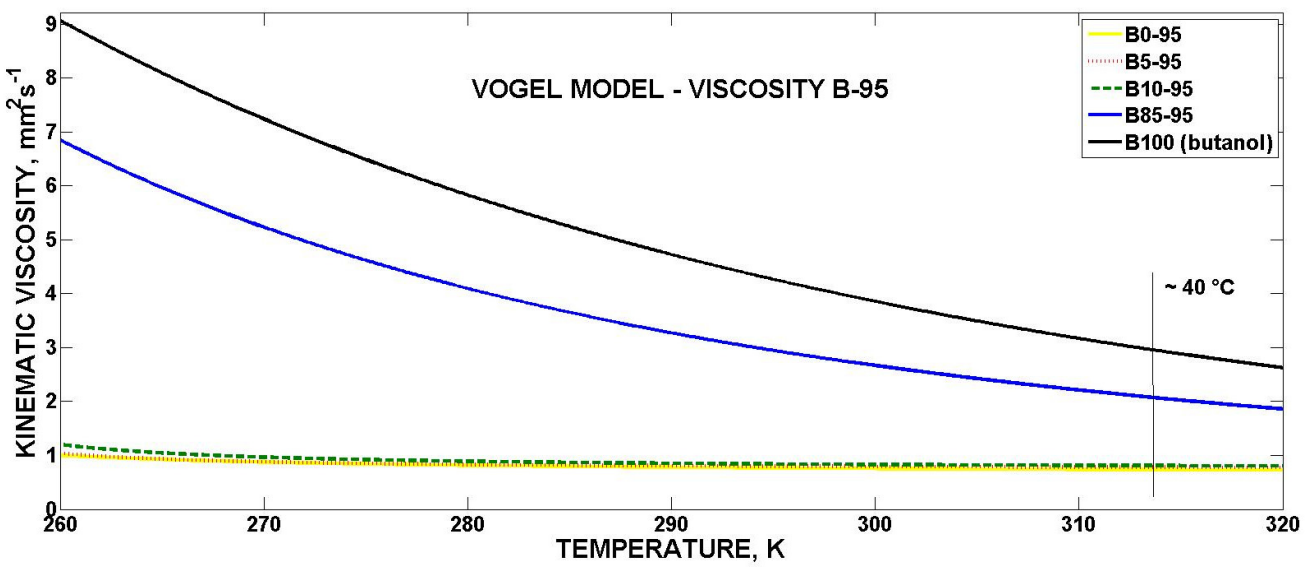

Figure 6. Vogel model graph for kinematic viscosity of biobutanol-gasoline (RON 95) blends. 


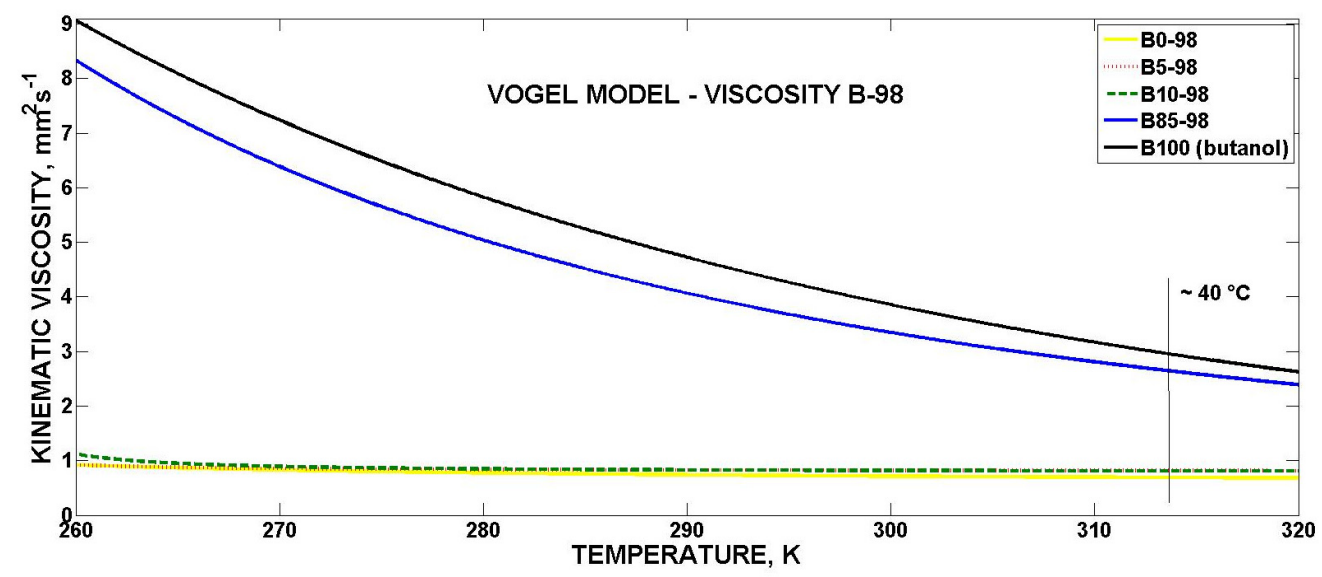

Figure 7. Vogel model graph for kinematic viscosity of biobutanol-gasoline (RON 98) blends.

\subsubsection{Mathematical Multivariate Models}

The created three-dimensional mathematical multivariate polynomial models (see Equations (11) and (12)) have a significant application potential, because it is possible to accurately calculate the exact value of the volumetric mass density or the kinematic viscosity for the whole temperatures range from -10 to $40{ }^{\circ} \mathrm{C}(\sim 263-313 \mathrm{~K})$ and with any possible concentration of the biobutanol in the gasoline (RON 95 and RON 98) with the obtained coefficients (Table 12). The volumetric mass density and kinematic viscosity values obtained by extrapolation from these multivariate models can also be used with a certain degree of accuracy.

From the three-dimensional graphs using the colour scale, it can be clearly seen that the lowest values (blue colour) of the volumetric mass density (Figures 8 and 9) and kinematic viscosity (Figures 10 and 11) are reached in the biobutanol-gasoline blends with a concentration below about $40 \mathrm{vol} . \%$ and at temperatures higher than $0{ }^{\circ} \mathrm{C}(\sim 273 \mathrm{~K})$; on the contrary, the highest values (yellow colour) were reached by the biobutanol-gasoline blends above 80 vol. $\%$ of biobutanol and at low temperatures $\left(<0{ }^{\circ} \mathrm{C}\right)$. The temperature dependence of the volumetric mass density or the kinematic viscosity and the effect of the biobutanol concentration in gasoline (RON 95 and RON 98) prove a nonlinear dependence like with the bioethanol-gasoline behaviour described in $[19,25]$.

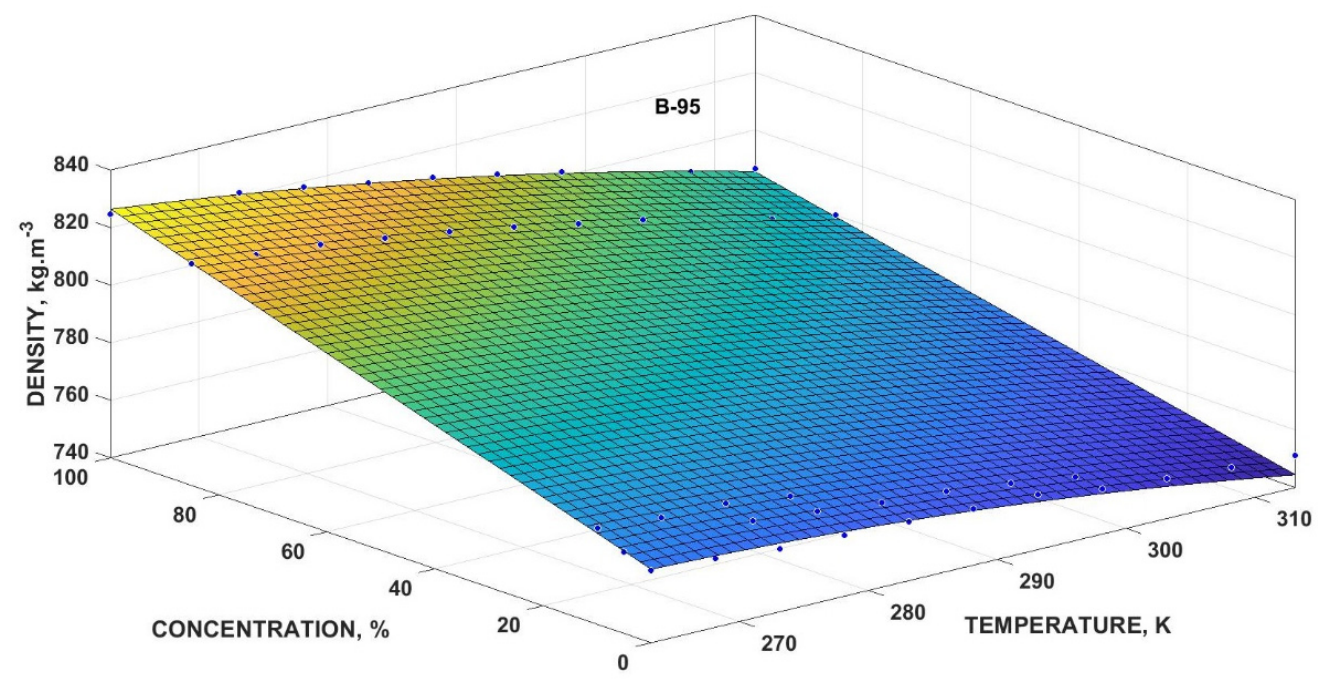

Figure 8. Three-dimensional graph created using multivariate polynomial model for volumetric mass density of biobutanol-gasoline (RON 95) blends. Experimental data are presented as the mean $(N=5)$ for selected temperatures and concentrations. 


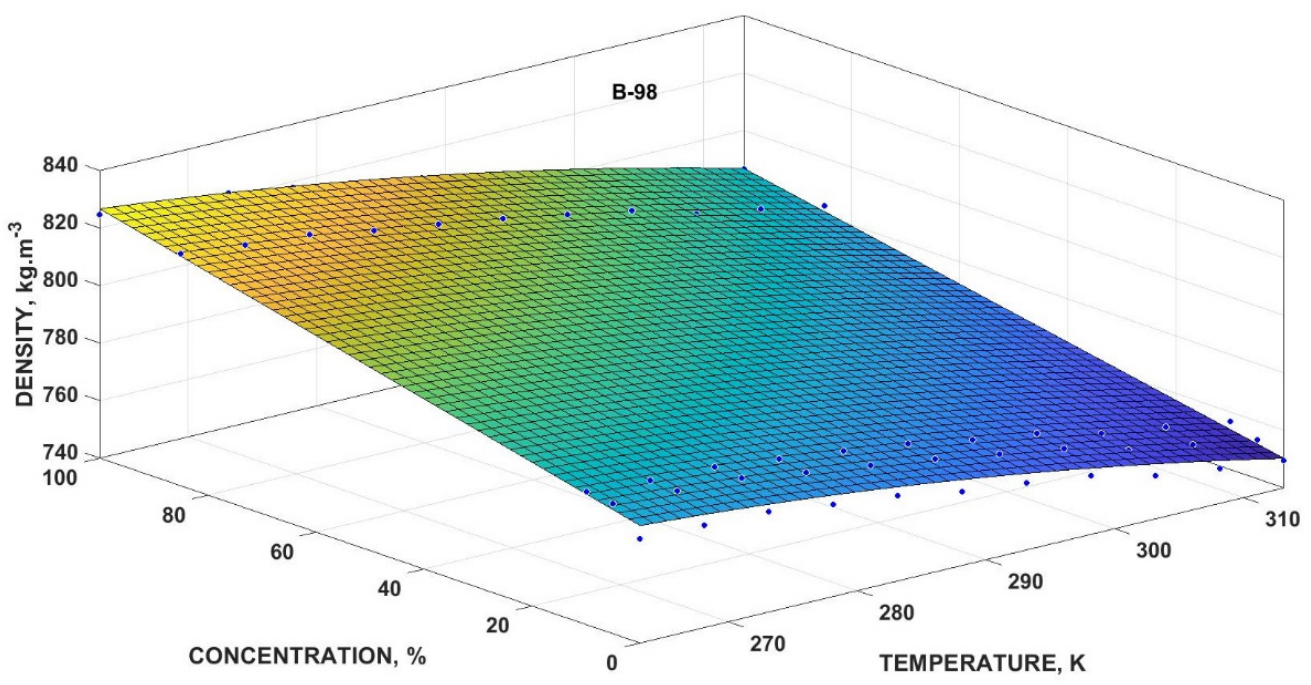

Figure 9. Three-dimensional graph created using multivariate polynomial model for volumetric mass density of biobutanol-gasoline (RON 98) blends. Experimental data are presented as the mean $(N=5)$ for selected temperatures and concentrations.

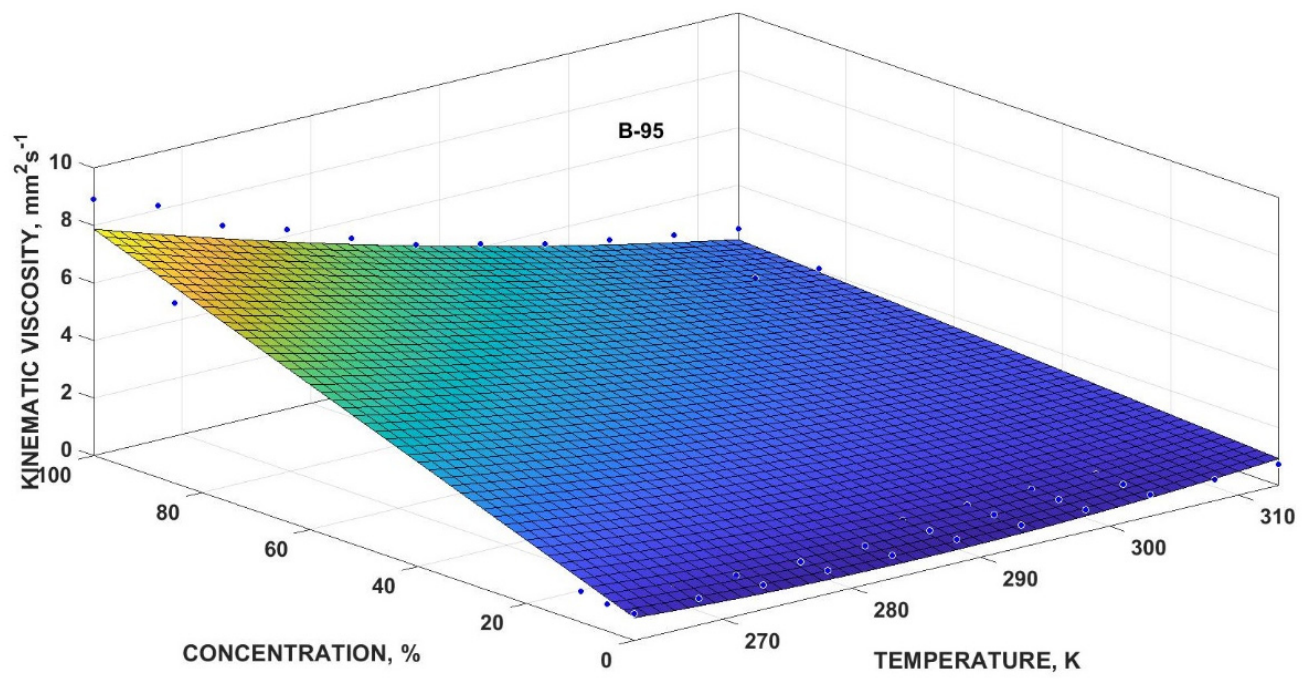

Figure 10. Three-dimensional graph created using multivariate polynomial model for kinematic viscosity of biobutanol-gasoline (RON 95) blends. Experimental data are presented as the mean $(N=20)$ for selected temperatures and concentrations.

Table 12. Coefficients of polynomial multivariate models and statistical indicators $\left(R^{2}\right.$-coefficient of determination, SSE—sum of squared estimate of errors).

\begin{tabular}{|c|c|c|c|c|c|c|c|}
\hline Volumetric Mass Density & $\begin{array}{c}x_{0} \\
\left(\mathrm{~kg} \cdot \mathrm{m}^{-3}\right)\end{array}$ & $\begin{array}{c}x_{1} \\
\left(\mathrm{~K}^{-1} \cdot \mathrm{kg} \cdot \mathrm{m}^{-3}\right)\end{array}$ & $\begin{array}{c}x_{2} \\
\left(\mathrm{~kg} \cdot \mathrm{m}^{-3}\right)\end{array}$ & $\begin{array}{c}x_{3} \\
\left(\mathrm{~K}^{-2} \cdot \mathrm{kg} \cdot \mathrm{m}^{-3}\right)\end{array}$ & $\begin{array}{c}x_{4} \\
\left(\mathrm{~K}^{-1} \cdot \mathrm{kg} \cdot \mathrm{m}^{-3}\right)\end{array}$ & $R^{2}$ & SSE \\
\hline Bx-95 & 358.4 & 3.202 & 1.649 & -0.006287 & -0.003953 & 0.9944 & 178.1 \\
\hline Bx-98 & 375.2 & 3.350 & 0.9477 & -0.006874 & -0.001859 & 0.9902 & 239.7 \\
\hline Kinematic Viscosity & $\begin{array}{c}y_{0} \\
\left(\mathrm{~mm}^{2} \cdot \mathrm{s}^{-1}\right)\end{array}$ & $\begin{array}{c}y_{1} \\
\left(\mathrm{~K}^{-1} \cdot \mathrm{mm}^{2} \cdot \mathrm{s}^{-1}\right)\end{array}$ & $\begin{array}{c}y_{2} \\
\left(\mathrm{~mm}^{2} \cdot \mathrm{s}^{-1}\right)\end{array}$ & $\left(\mathrm{K}^{-2} \cdot \mathrm{mm}^{y_{3}} \cdot \mathrm{s}^{-1}\right)$ & $\begin{array}{c}y_{4} \\
\left(\mathrm{~K}^{-1} \cdot \mathrm{mm}^{2} \cdot \mathrm{s}^{-1}\right)\end{array}$ & $R^{2}$ & SSE \\
\hline Bx-95 & 52.91 & -0.3668 & 0.3809 & 0.0006412 & -0.001178 & 0.9715 & 7.021 \\
\hline Bx-98 & 54.61 & -0.3801 & 0.4105 & 0.0006663 & -0.001265 & 0.9897 & 2.999 \\
\hline
\end{tabular}




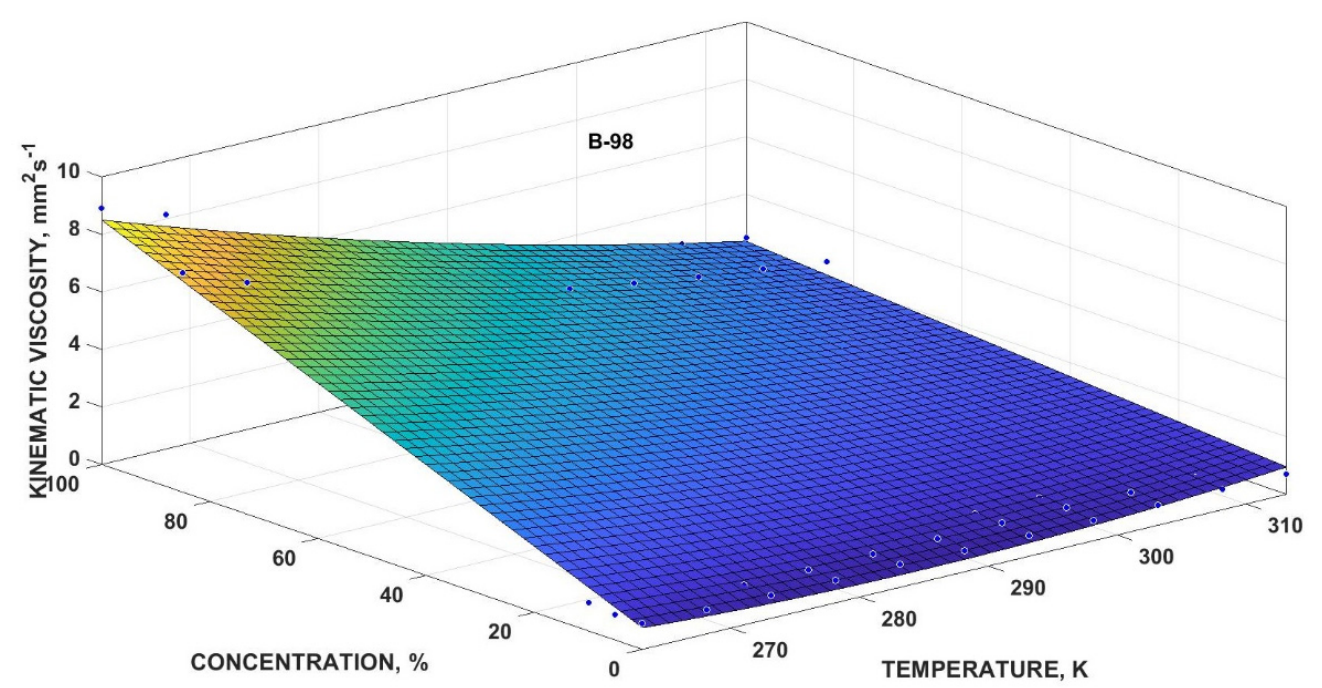

Figure 11. Three-dimensional graph created using multivariate polynomial model for kinematic viscosity of biobutanol-gasoline (RON 98) blends. Experimental data are presented as the mean $(N=20)$ for selected temperatures and concentrations.

\section{Conclusions}

It must be stated that the obtained results, especially the coefficients of the mathematical models, are usable for the advanced numerical modelling of flow properties of biobutanol-gasoline blends; for example, the modelling of the pressure drop, shear stress, maximum and mean flow velocity, volume and mass flow, two-dimensional and three-dimensional velocity profiles, friction factor, laminar and turbulent flow (Reynolds number), etc.

The results are certainly applicable in industrial practice. For instance, the models with the coefficients could be used to set a car control unit, which would be able to evaluate the exact amount of fuel needed for injection into the combustion chamber according to the current concentration of the biobutanol in the gasoline (RON 95 and RON 98) and current temperature of the fuel, because, as this paper stated, these can affect the fuel volumetric mass density and the dynamic/kinematic viscosity.

It is appropriate to emphasise these research findings:

- The RON 98 gasoline reaches higher values in the volumetric mass density than the RON 95 gasoline.

- The volumetric mass density of the biobutanol-gasoline blends almost linearly (coefficient of exponential model $b \rightarrow 0$ ) decreases with an increasing temperature for all concentrations.

- The RON 98 gasoline reaches lower values in the dynamic and kinematic viscosity than the RON 95 gasoline.

- The dynamic and kinematic viscosity of the biobutanol-gasoline blends nonlinear decreases with an increasing temperature for all concentrations.

- The biobutanol-gasoline blends with a higher biobutanol content have higher dynamic and kinematic viscosity values.

- The dynamic and kinematic viscosity of the biobutanol-gasoline blends with a content up to 10 vol.\% of biobutanol is almost the same as the dynamic and kinematic viscosity of the RON 95 and RON 98 gasolines without a biocomponent $(p<0.05)$.

- The dynamic and kinematic viscosity of the biobutanol-gasoline blends with a content up to 85 vol. \% of biobutanol is similar to the dynamic and kinematic viscosity of the pure biobutanol $(p<0.05)$. 
Author Contributions: Conceptualization, D.T. and V.K.; methodology, D.T., A.P., and V.K.; software, A.P.; validation, D.B.N., A.W.; formal analysis, D.T.; investigation, D.T.; resources, V.K.; data curation, D.B.; writing—original draft preparation, D.T.; writing—review and editing, D.B., D.B.N., and A.W.; supervision, V.K.; project administration, V.K.; funding acquisition, D.T. and V.K. All authors have read and agreed to the published version of the manuscript.

Funding: This research was funded by the Internal Grant Agency of the Faculty of AgriSciences no. AF-IGA-2020-IP060.

Institutional Review Board Statement: Not applicable.

Informed Consent Statement: Not applicable.

Data Availability Statement: Data is contained within the article.

Acknowledgments: Authors would like to acknowledge the LSU AgCenter for the proofreading and scientific collaboration on this manuscript.

Conflicts of Interest: The authors declare no conflict of interest. The funders had no role in the design of the study; in the collection, analyses, or interpretation of data; in the writing of the manuscript, or in the decision to publish the results.

\section{Appendix A}

Table A1. Values of volumetric mass density of biobutanol-gasoline (RON 95) blends (mean \pm Scheme 5).

\begin{tabular}{ccccccc}
\hline \multirow{2}{*}{ Temperature $\left({ }^{\circ} \mathbf{C}\right)$} & Temperature (K) & \multicolumn{5}{c}{ Volumetric Mass Density RON 95 (kg. m $\left.{ }^{-3}\right)$} \\
\cline { 3 - 7 } & & B0 & B5 & B10 & B85 & B100 \\
\hline-10 & 263.15 & $765.1 \pm 1.49$ & $768.3 \pm 1.63$ & $773.5 \pm 1.41$ & $817.1 \pm 1.62$ & $824.6 \pm 1.60$ \\
-5 & 268.15 & $763.8 \pm 1.56$ & $766.7 \pm 1.53$ & $771.5 \pm 1.49$ & $814.8 \pm 1.81$ & $822.8 \pm 1.50$ \\
0 & 273.15 & $761.9 \pm 1.27$ & $768.4 \pm 1.40$ & $771.1 \pm 1.52$ & $813.1 \pm 1.58$ & $821.3 \pm 1.31$ \\
5 & 278.15 & $761.1 \pm 1.42$ & $766.2 \pm 1.48$ & $768.3 \pm 1.50$ & $809.7 \pm 1.58$ & $817.9 \pm 1.60$ \\
10 & 283.15 & $760.6 \pm 1.61$ & $764.0 \pm 1.61$ & $765.2 \pm 1.45$ & $806.5 \pm 1.81$ & $813.9 \pm 1.27$ \\
15 & 288.15 & $759.6 \pm 1.53$ & $762.4 \pm 1.52$ & $762.6 \pm 1.39$ & $803.0 \pm 1.83$ & $810.5 \pm 1.41$ \\
20 & 293.15 & $759.0 \pm 1.48$ & $759.7 \pm 1.38$ & $760.0 \pm 1.61$ & $798.7 \pm 1.53$ & $806.3 \pm 1.44$ \\
25 & 298.15 & $755.8 \pm 1.42$ & $756.5 \pm 1.29$ & $756.6 \pm 1.41$ & $794.6 \pm 1.57$ & $801.7 \pm 1.47$ \\
30 & 303.15 & $753.8 \pm 1.29$ & $750.3 \pm 1.47$ & $751.3 \pm 1.48$ & $787.9 \pm 1.55$ & $794.2 \pm 1.78$ \\
35 & 308.15 & $752.3 \pm 1.25$ & $747.2 \pm 1.62$ & $749.4 \pm 1.37$ & $784.2 \pm 1.58$ & $790.8 \pm 1.52$ \\
40 & 313.15 & $751.1 \pm 1.55$ & $744.2 \pm 1.60$ & $747.6 \pm 1.24$ & $780.2 \pm 1.48$ & $786.6 \pm 1.57$ \\
\hline
\end{tabular}

Table A2. Values of volumetric mass density of biobutanol-gasoline (RON 98) blends (mean \pm standard deviation, $N=5$ ).

\begin{tabular}{ccccccc}
\hline \multirow{2}{*}{ Temperature $\left({ }^{\circ} \mathbf{C}\right)$} & Temperature (K) & \multicolumn{4}{c}{ Volumetric Mass Density RON 98 (kg. m $\left.{ }^{-3}\right)$} \\
\cline { 3 - 7 } & & B0 & B5 & B10 & B85 & B100 \\
\hline-10 & 263.15 & $776.1 \pm 1.63$ & $785.1 \pm 1.40$ & $786.3 \pm 1.33$ & $820.6 \pm 1.42$ & $824.6 \pm 1.60$ \\
-5 & 268.15 & $775.6 \pm 1.41$ & $784.4 \pm 1.37$ & $784.7 \pm 1.36$ & $818.3 \pm 1.37$ & $822.8 \pm 1.50$ \\
0 & 273.15 & $775.0 \pm 1.26$ & $783.3 \pm 1.35$ & $783.9 \pm 1.27$ & $816.5 \pm 1.39$ & $821.3 \pm 1.31$ \\
5 & 278.15 & $772.1 \pm 1.37$ & $779.9 \pm 1.36$ & $781.3 \pm 1.38$ & $812.7 \pm 1.49$ & $817.9 \pm 1.60$ \\
10 & 283.15 & $769.6 \pm 1.40$ & $777.0 \pm 1.57$ & $778.7 \pm 1.40$ & $809.5 \pm 1.44$ & $813.9 \pm 1.27$ \\
15 & 288.15 & $765.6 \pm 1.29$ & $773.8 \pm 1.47$ & $775.9 \pm 1.45$ & $806.0 \pm 1.44$ & $810.5 \pm 1.41$ \\
20 & 293.15 & $763.2 \pm 1.12$ & $770.1 \pm 1.38$ & $771.9 \pm 1.36$ & $802.0 \pm 1.48$ & $806.3 \pm 1.44$ \\
25 & 298.15 & $760.4 \pm 1.17$ & $766.6 \pm 1.19$ & $768.7 \pm 1.27$ & $797.9 \pm 1.50$ & $801.7 \pm 1.47$ \\
30 & 303.15 & $754.9 \pm 1.35$ & $760.7 \pm 1.29$ & $763.2 \pm 1.43$ & $791.5 \pm 1.46$ & $794.2 \pm 1.78$ \\
35 & 308.15 & $752.2 \pm 1.40$ & $757.3 \pm 1.27$ & $760.1 \pm 1.30$ & $787.6 \pm 1.40$ & $790.8 \pm 1.52$ \\
40 & 313.15 & $749.4 \pm 1.43$ & $753.6 \pm 1.33$ & $756.8 \pm 1.32$ & $783.4 \pm 1.42$ & $786.6 \pm 1.57$ \\
\hline
\end{tabular}


Table A3. Values of dynamic viscosity of biobutanol-gasoline (RON 95) blends (mean \pm standard deviation, $N=20$ ).

\begin{tabular}{|c|c|c|c|c|c|c|}
\hline \multirow{2}{*}{ Temperature $\left({ }^{\circ} \mathrm{C}\right)$} & \multirow{2}{*}{ Temperature (K) } & \multicolumn{5}{|c|}{ Dynamic Viscosity RON 95 (mPa·s) } \\
\hline & & B0 & B5 & B10 & B85 & B100 \\
\hline-10 & 263.15 & $0.72 \pm 0.025^{\mathrm{j}, \mathrm{k}}$ & $0.73 \pm 0.021^{\mathrm{m}}$ & $0.83 \pm 0.010^{\circ}$ & $5.12 \pm 0.026^{\omega}$ & $7.34 \pm 0.025^{\lambda}$ \\
\hline-5 & 268.15 & $0.70 \pm 0.018^{\mathrm{d}, \mathrm{e}, \mathrm{f}, \mathrm{g}, \mathrm{h}, \mathrm{i}}$ & $0.71 \pm 0.023^{1}$ & $0.78 \pm 0.010^{\mathrm{n}}$ & $4.50 \pm 0.023^{\tau}$ & $6.71 \pm 0.027^{\delta}$ \\
\hline 0 & 273.15 & $0.64 \pm 0.035^{\mathrm{d}, \mathrm{e}, \mathrm{f}}$ & $0.66 \pm 0.014^{k}$ & $0.73 \pm 0.017^{\mathrm{m}}$ & $3.88 \pm 0.017^{\rho}$ & $5.69 \pm 0.025^{\eta}$ \\
\hline 5 & 278.15 & $0.61 \pm 0.035^{\mathrm{d}, \mathrm{e}, \mathrm{f}}$ & $0.63 \pm 0.019^{\mathrm{d}, \mathrm{e}}$ & $0.69 \pm 0.015^{1}$ & $3.45 \pm 0.017^{z}$ & $5.11 \pm 0.031 \omega$ \\
\hline 10 & 283.15 & $0.60 \pm 0.018^{\mathrm{e}, \mathrm{f}, \mathrm{g}, \mathrm{h}, \mathrm{i}, \mathrm{j}}$ & $0.63 \pm 0.015^{\mathrm{d}, \mathrm{e}, \mathrm{f}, \mathrm{g}}$ & $0.64 \pm 0.012^{\mathrm{i}, \mathrm{j}, \mathrm{k}}$ & $3.05 \pm 0.017^{x}$ & $4.38 \pm 0.016^{\pi}$ \\
\hline 15 & 288.15 & $0.61 \pm 0.032^{\mathrm{d}, \mathrm{e}, \mathrm{f}}$ & $0.62 \pm 0.013^{\mathrm{d}, \mathrm{e}, \mathrm{f}}$ & $0.64 \pm 0.010^{h, i, j}$ & $2.75 \pm 0.015^{\mathrm{v}}$ & $3.76 \pm 0.012^{\beta}$ \\
\hline 20 & 293.15 & $0.59 \pm 0.025^{c, d}$ & $0.62 \pm 0.016^{\mathrm{d}, \mathrm{e}, \mathrm{f}, \mathrm{g}, \mathrm{h}}$ & $0.64 \pm 0.014^{\mathrm{f}, \mathrm{g}, \mathrm{h}, \mathrm{i}, \mathrm{j}}$ & $2.47 \pm 0.007^{\mathrm{t}}$ & $3.32 \pm 0.010^{y}$ \\
\hline 25 & 298.15 & $0.58 \pm 0.031^{b, c}$ & $0.62 \pm 0.015^{\mathrm{d}, \mathrm{e}, \mathrm{f}}$ & $0.64 \pm 0.010^{g, h, i, j, j}$ & $2.21 \pm 0.011^{\mathrm{s}}$ & $2.88 \pm 0.010^{w}$ \\
\hline 30 & 303.15 & $0.57 \pm 0.024^{b}$ & $0.60 \pm 0.015^{c, d}$ & $0.63 \pm 0.012^{e, f, g, h, i, j}$ & $1.97 \pm 0.010^{\mathrm{r}}$ & $2.53 \pm 0.009^{u}$ \\
\hline 35 & 308.15 & $0.56 \pm 0.021^{b}$ & $0.58 \pm 0.021^{b}$ & $0.62 \pm 0.010^{\mathrm{d}, \mathrm{e}, \mathrm{f}}$ & $1.79 \pm 0.010^{q}$ & $2.21 \pm 0.010^{\mathrm{s}}$ \\
\hline 40 & 313.15 & $0.54 \pm 0.018^{a}$ & $0.57 \pm 0.015^{b}$ & $0.61 \pm 0.013^{\mathrm{d}, \mathrm{e}}$ & $1.61 \pm 0.012 \mathrm{p}$ & $1.95 \pm 0.010^{\mathrm{r}}$ \\
\hline
\end{tabular}

The same indices indicate that no statistically significant difference was demonstrated between the respective dynamic viscosity at the significance level of $p=0.95$.

Table A4. Values of dynamic viscosity of biobutanol-gasoline (RON 98) blends (mean \pm standard deviation, $N=20$ ).

\begin{tabular}{|c|c|c|c|c|c|c|}
\hline \multirow{2}{*}{ Temperature $\left({ }^{\circ} \mathrm{C}\right)$} & \multirow{2}{*}{ Temperature (K) } & \multicolumn{5}{|c|}{ Dynamic Viscosity RON 98 (mPa.s) } \\
\hline & & B0 & B5 & B10 & B85 & B100 \\
\hline-10 & 263.15 & $0.69 \pm 0.027^{i}$ & $0.70 \pm 0.010^{\mathrm{k}}$ & $0.77 \pm 0.011^{\mathrm{m}}$ & $4.89 \pm 0.019^{\tau}$ & $7.34 \pm 0.025^{\lambda}$ \\
\hline-5 & 268.15 & $0.65 \pm 0.029 \mathrm{~d}, \mathrm{e}$ & $0.68 \pm 0.010^{j}$ & $0.74 \pm 0.010^{1}$ & $4.39 \pm 0.016^{\pi}$ & $6.71 \pm 0.027^{\delta}$ \\
\hline 0 & 273.15 & $0.62 \pm 0.030^{\mathrm{d}, \mathrm{e}, \mathrm{f}}$ & $0.65 \pm 0.008^{\mathrm{f}, \mathrm{g}, \mathrm{h}, \mathrm{i}}$ & $0.69 \pm 0.006^{\mathrm{j}, \mathrm{k}}$ & $3.81 \pm 0.011^{\rho}$ & $5.69 \pm 0.025^{\eta}$ \\
\hline 5 & 278.15 & $0.60 \pm 0.029$ e,f,g,h,i & $0.65 \pm 0.007^{\mathrm{h}, \mathrm{i}}$ & $0.65 \pm 0.007^{\mathrm{f}, \mathrm{g}, \mathrm{h}, \mathrm{i}}$ & $3.28 \pm 0.010^{y}$ & $5.11 \pm 0.031 \omega$ \\
\hline 10 & 283.15 & $0.61 \pm 0.031^{\mathrm{d}, \mathrm{e}}$ & $0.65 \pm 0.008^{h, i}$ & $0.63 \pm 0.009 \mathrm{~d}, \mathrm{e}$ & $2.92 \pm 0.010^{x}$ & $4.38 \pm 0.016^{\pi}$ \\
\hline 15 & 288.15 & $0.57 \pm 0.030^{\mathrm{e}, \mathrm{f}, \mathrm{g}}$ & $0.65 \pm 0.004^{g, h, i}$ & $0.63 \pm 0.010^{\mathrm{d}, \mathrm{e}, \mathrm{f}}$ & $2.62 \pm 0.013^{\mathrm{v}}$ & $3.76 \pm 0.012^{\beta}$ \\
\hline 20 & 293.15 & $0.55 \pm 0.022^{\mathrm{d}, \mathrm{e}, \mathrm{f}}$ & $0.65 \pm 0.008^{h, i}$ & $0.64 \pm 0.010^{\mathrm{e}, \mathrm{f}, \mathrm{g}, \mathrm{h}}$ & $2.31 \pm 0.012^{t}$ & $3.32 \pm 0.010^{z}$ \\
\hline 25 & 298.15 & $0.54 \pm 0.026^{\mathrm{d}, \mathrm{e}}$ & $0.63 \pm 0.007^{\mathrm{d}, \mathrm{e}}$ & $0.64 \pm 0.010^{\mathrm{e}, \mathrm{f}, \mathrm{g}, \mathrm{h}}$ & $2.09 \pm 0.010^{\mathrm{r}}$ & $2.88 \pm 0.010^{w}$ \\
\hline 30 & 303.15 & $0.53 \pm 0.035^{\mathrm{a}, \mathrm{b}}$ & $0.63 \pm 0.006^{\mathrm{d}, \mathrm{e}}$ & $0.63 \pm 0.006^{\mathrm{d}, \mathrm{e}}$ & $1.88 \pm 0.011^{p}$ & $2.53 \pm 0.009^{\mathrm{u}}$ \\
\hline 35 & 308.15 & $0.53 \pm 0.028^{a}$ & $0.61 \pm 0.008^{b, c}$ & $0.63 \pm 0.004^{\mathrm{d}, \mathrm{e}}$ & $1.69 \pm 0.010^{\circ}$ & $2.21 \pm 0.010^{\mathrm{s}}$ \\
\hline 40 & 313.15 & $0.52 \pm 0.018^{\mathrm{a}}$ & $0.60 \pm 0.009^{a, b}$ & $0.62 \pm 0.010^{c, d}$ & $1.50 \pm 0.008^{n}$ & $1.95 \pm 0.010^{q}$ \\
\hline
\end{tabular}

The same indices indicate that no statistically significant difference was demonstrated between the respective dynamic viscosity at the significance level of $p=0.95$.

Table A5. Values of kinematic viscosity of biobutanol-gasoline (RON 95) blends (mean \pm standard deviation, $N=20$ ).

\begin{tabular}{|c|c|c|c|c|c|c|}
\hline \multirow{2}{*}{ Temperature $\left({ }^{\circ} \mathrm{C}\right)$} & \multirow{2}{*}{ Temperature (K) } & \multicolumn{5}{|c|}{ Kinematic Viscosity RON $95\left(\mathrm{~mm}^{2} \cdot \mathrm{s}^{-1}\right)$} \\
\hline & & B0 & B5 & B10 & B85 & B100 \\
\hline-10 & 263.15 & $0.94 \pm 0.006^{1, m, n}$ & $0.96 \pm 0.024^{n}$ & $1.07 \pm 0.011^{\mathrm{p}}$ & $6.27 \pm 0.019^{\tau}$ & $8.90 \pm 0.016^{\beta}$ \\
\hline-5 & 268.15 & $0.92 \pm 0.012^{\mathrm{k}, \mathrm{l}}$ & $0.93 \pm 0.024^{1, \mathrm{~m}}$ & $1.01 \pm 0.011^{\circ}$ & $5.52 \pm 0.015^{\theta}$ & $8.16 \pm 0.021^{\rho}$ \\
\hline 0 & 273.15 & $0.84 \pm 0.021^{i, j}$ & $0.86 \pm 0.011^{j}$ & $0.95 \pm 0.020^{\mathrm{m}, \mathrm{n}}$ & $4.77 \pm 0.012^{\delta}$ & $6.93 \pm 0.019^{\pi}$ \\
\hline 5 & 278.15 & $0.80 \pm 0.026^{\mathrm{e}, \mathrm{f}}$ & $0.81 \pm 0.012^{\mathrm{e}, \mathrm{f}}$ & $0.90 \pm 0.018^{\mathrm{k}}$ & $4.26 \pm 0.013^{\lambda}$ & $6.25 \pm 0.015^{\tau}$ \\
\hline 10 & 283.15 & $0.79 \pm 0.027^{\mathrm{d}, \mathrm{e}}$ & $0.81 \pm 0.011^{\mathrm{e}, \mathrm{f}}$ & $0.84 \pm 0.014^{g, h, i, j}$ & $3.78 \pm 0.013^{\mathrm{y}}$ & $5.38 \pm 0.016^{\omega}$ \\
\hline 15 & 288.15 & $0.80 \pm 0.021^{\mathrm{e}, \mathrm{f}}$ & $0.81 \pm 0.012^{\mathrm{e}, \mathrm{f}}$ & $0.84 \pm 0.012^{h, i, j}$ & $3.45 \pm 0.011^{w}$ & $4.63 \pm 0.022^{\eta}$ \\
\hline 20 & 293.15 & $0.78 \pm 0.025^{\mathrm{c}, \mathrm{d}}$ & $0.82 \pm 0.014^{\mathrm{f}, \mathrm{g}, \mathrm{h}}$ & $0.84 \pm 0.017^{g, h, i}$ & $3.09 \pm 0.003^{\mathrm{u}}$ & $4.12 \pm 0.017^{\mathrm{z}}$ \\
\hline 25 & 298.15 & $0.77 \pm 0.020^{b, c, d}$ & $0.82 \pm 0.012^{\mathrm{f}, \mathrm{g}}$ & $0.85 \pm 0.017^{i, j}$ & $2.78 \pm 0.008^{t}$ & $3.59 \pm 0.020^{x}$ \\
\hline 30 & 303.15 & $0.76 \pm 0.015^{b, c}$ & $0.80 \pm 0.012^{\mathrm{e}, \mathrm{f}}$ & $0.84 \pm 0.014^{\mathrm{g}, \mathrm{h}, \mathrm{i}}$ & $2.50 \pm 0.008^{\mathrm{s}}$ & $3.18 \pm 0.009^{v}$ \\
\hline 35 & 308.15 & $0.74 \pm 0.016^{b}$ & $0.78 \pm 0.025^{\mathrm{c}, \mathrm{d}}$ & $0.83 \pm 0.012^{f, g, h, i}$ & $2.28 \pm 0.008^{\mathrm{r}}$ & $2.80 \pm 0.015^{\mathrm{t}}$ \\
\hline 40 & 313.15 & $0.72 \pm 0.013^{\mathrm{a}}$ & $0.77 \pm 0.012^{b, c, d}$ & $0.82 \pm 0.016^{\mathrm{f}, \mathrm{g}}$ & $2.06 \pm 0.011 \mathrm{q}$ & $2.48 \pm 0.021^{\mathrm{s}}$ \\
\hline
\end{tabular}

The same indices indicate that no statistically significant difference was demonstrated between the respective kinematic viscosity at the significance level of $p=0.95$. 
Table A6. Values of kinematic viscosity of biobutanol-gasoline (RON 98) blends (mean \pm standard deviation, $N=20$ ).

\begin{tabular}{|c|c|c|c|c|c|c|}
\hline \multirow{2}{*}{ Temperature $\left({ }^{\circ} \mathrm{C}\right)$} & \multirow{2}{*}{ Temperature (K) } & \multicolumn{5}{|c|}{ Kinematic Viscosity RON $98\left(\mathrm{~mm}^{2} \cdot \mathrm{s}^{-1}\right)$} \\
\hline & & B0 & B5 & B10 & B85 & B100 \\
\hline-10 & 263.15 & $0.89 \pm 0.010^{\mathrm{j}, \mathrm{k}}$ & $0.89 \pm 0.011^{\mathrm{n}}$ & $0.98 \pm 0.012 \mathrm{p}$ & $5.96 \pm 0.013^{\tau}$ & $8.90 \pm 0.016^{\beta}$ \\
\hline-5 & 268.15 & $0.84 \pm 0.006^{c, d, e, f}$ & $0.87 \pm 0.011^{1, \mathrm{~m}}$ & $0.94 \pm 0.011^{\circ}$ & $5.37 \pm 0.011^{\theta}$ & $8.16 \pm 0.021^{\rho}$ \\
\hline 0 & 273.15 & $0.80 \pm 0.008^{\mathrm{d}, \mathrm{e}, \mathrm{f}, \mathrm{g}}$ & $0.83 \pm 0.009^{\mathrm{d}, \mathrm{e}, \mathrm{f}, \mathrm{g}, \mathrm{h}, \mathrm{i}}$ & $0.88 \pm 0.006^{\mathrm{m}, \mathrm{n}}$ & $4.67 \pm 0.006^{\omega}$ & $6.93 \pm 0.019^{\pi}$ \\
\hline 5 & 278.15 & $0.78 \pm 0.012^{\mathrm{g}, \mathrm{h}, \mathrm{i}, \mathrm{j}, \mathrm{k}}$ & $0.83 \pm 0.008^{\mathrm{h}, \mathrm{i}, \mathrm{j}, \mathrm{k}}$ & $0.83 \pm 0.008^{\mathrm{e}, \mathrm{f}, \mathrm{g}, \mathrm{h}, \mathrm{i}, \mathrm{j}}$ & $4.04 \pm 0.005^{\lambda}$ & $6.25 \pm 0.015^{\tau}$ \\
\hline 10 & 283.15 & $0.79 \pm 0.014^{\mathrm{d}, \mathrm{e}, \mathrm{f}, \mathrm{g}}$ & $0.84 \pm 0.009^{\mathrm{i}, \mathrm{j}, \mathrm{k}}$ & $0.81 \pm 0.010^{\mathrm{b}, \mathrm{c}, \mathrm{d}, \mathrm{e}}$ & $3.61 \pm 0.005^{\mathrm{z}}$ & $5.38 \pm 0.016^{\omega}$ \\
\hline 15 & 288.15 & $0.75 \pm 0.012^{\mathrm{g}, \mathrm{h}, \mathrm{i}, \mathrm{j}, \mathrm{k}, \mathrm{k}}$ & $0.84 \pm 0.004^{\mathrm{i}, \mathrm{j}, \mathrm{k}}$ & $0.81 \pm 0.011^{\mathrm{d}, \mathrm{e}, \mathrm{f}, \mathrm{g}}$ & $3.25 \pm 0.010^{y}$ & $4.63 \pm 0.022^{\eta}$ \\
\hline 20 & 293.15 & $0.72 \pm 0.013^{\mathrm{e}, \mathrm{f}, \mathrm{g}, \mathrm{h}, \mathrm{i}, \mathrm{j}, \mathrm{j}}$ & $0.84 \pm 0.009 \mathrm{k}, 1$ & $0.83 \pm 0.012^{\mathrm{f}, \mathrm{g}, \mathrm{h}, \mathrm{i}, \mathrm{j}}$ & $2.88 \pm 0.010^{w}$ & $4.12 \pm 0.017^{z}$ \\
\hline 25 & 298.15 & $0.71 \pm 0.013^{\mathrm{d}, \mathrm{e}, \mathrm{f}, \mathrm{g}, \mathrm{h}, \mathrm{h}, \mathrm{i}, \mathrm{j}}$ & $0.82 \pm 0.008^{\mathrm{d}, \mathrm{e}, \mathrm{f}, \mathrm{g}, \mathrm{h}}$ & $0.83 \pm 0.011^{\mathrm{g}, \mathrm{h}, \mathrm{i}, \mathrm{j}, \mathrm{k}}$ & $2.62 \pm 0.008^{u}$ & $3.59 \pm 0.020^{x}$ \\
\hline 30 & 303.15 & $0.70 \pm 0.011^{\mathrm{a}, \mathrm{b}}$ & $0.83 \pm 0.007^{\mathrm{e}, \mathrm{f}, \mathrm{g}, \mathrm{h}, \mathrm{i}, \mathrm{j}}$ & $0.83 \pm 0.006^{\mathrm{d}, \mathrm{e}, \mathrm{f}, \mathrm{g}, \mathrm{h}, \mathrm{i}}$ & $2.38 \pm 0.010^{\mathrm{s}}$ & $3.18 \pm 0.009^{\mathrm{v}}$ \\
\hline 35 & 308.15 & $0.71 \pm 0.009^{\mathrm{a}}$ & $0.81 \pm 0.009^{b, c, d}$ & $0.83 \pm 0.004^{\mathrm{e}, \mathrm{f}, \mathrm{g}, \mathrm{h}, \mathrm{i}, \mathrm{j}}$ & $2.15 \pm 0.008^{r}$ & $2.80 \pm 0.015^{\mathrm{t}}$ \\
\hline 40 & 313.15 & $0.69 \pm 0.009^{a}$ & $0.79 \pm 0.011^{\mathrm{a}, \mathrm{b}, \mathrm{c}}$ & $0.81 \pm 0.012^{\mathrm{d}, \mathrm{e}, \mathrm{f}, \mathrm{g}}$ & $1.92 \pm 0.007^{\mathrm{q}}$ & $2.48 \pm 0.021^{\mathrm{s}}$ \\
\hline
\end{tabular}

The same indices indicate that no statistically significant difference was demonstrated between the respective kinematic viscosity at the significance level of $p=0.95$.

\section{References}

1. Pereira, L.G.; Chagas, M.F.; Dias, M.O.S.; Cavalett, O.; Bonomi, A. Life cycle assessment of butanol production in sugarcane biorefineries in Brazil. J. Clean. Prod. 2015, 96,557-568. [CrossRef]

2. Arshad, M.; Zia, M.A.; Shah, F.A.; Ahmad, M. An overview of biofuel. In Perspectives on Water Usage for Biofuels Production; Springer: Cham, Switzerland, 2018; pp. 1-37.

3. Kokkinos, N.C.; Nikolaou, N.; Psaroudakis, N.; Mertis, K.; Mitkidou, S.; Mitropoulos, A.C. Two-step conversion of LLCN olefins to strong anti-knocking alcohol mixtures catalysed by Rh, Ru/TPPTS complexes in aqueous media. Catal. Today 2015, 247, 132-138. [CrossRef]

4. Hönig, V.; Kotek, M.; Orsák, M.; Hromádko, J. Use of biobutanol in gasoline engines. Listy Cukrov. Řepařské 2015, 131, 311-315.

5. Thangavelu, S.K.; Ahmed, A.S.; Ani, F.N. Review on bioethanol as alternative fuel for spark ignition engines. Renew. Sustain. Energy Rev. 2016, 56, 820-835. [CrossRef]

6. Marri, V.B.; Kotha, M.M.; Gaddale, A.P.R. Butanol and pentanol: The promising biofuels for CI engines-A review. Renew. Sustain. Energy Rev. 2017, 78, 1068-1088.

7. Festel, G.W. Biofuels-Economic aspects. Chem. Eng. Technol. 2008, 31, 715-720. [CrossRef]

8. Ramírez-Verduzco, L.F.; Rodríguez-Rodríguez, J.E.; Jaramillo-Jacob, A.D.R. Predicting cetane number, kinematic viscosity, density and higher heating value of biodiesel from its fatty acid methyl ester composition. Fuel 2012, 91, 102-111. [CrossRef]

9. Han, X.; Yang, Z.; Wang, M.; Tjong, J.; Zheng, M. Clean combustion of $\mathrm{n}$-butanol as a next generation biofuel for diesel engines. Appl. Energy 2017, 198, 347-359. [CrossRef]

10. Pugazhendhi, A.; Mathimani, T.; Varjani, S.; Rene, E.R.; Kumar, G.; Kim, S.-H.; Ponnusamy, V.K.; Yoon, J.-J. Biobutanol as a promising liquid fuel for the future-Recent updates and perspectives. Fuel 2019, 253, 637-646. [CrossRef]

11. Qureshi, N.; Meagher, M.; Huang, J.; Hutkins, R. Acetone butanol ethanol (ABE) recovery by pervaporation using silicalite-silicone composite membrane from fed-batch reactor of Clostridium acetobutylicum. J. Membr. Sci. 2001, 187, 93-102. [CrossRef]

12. García, V.; Päkkilä, J.; Ojamo, H.; Muurinen, E.; Keiski, R.L. Challenges in biobutanol production: How to improve the efficiency? Renew. Sustain. Energy Rev. 2011, 15, 964-980. [CrossRef]

13. Jin, C.; Yao, M.; Liu, H.; Lee, C.-F.F.; Ji, J. Progress in the production and application of n-butanol as a biofuel. Renew. Sustain. Energy Rev. 2011, 15, 4080-4106. [CrossRef]

14. Tredici, M.R. Photobiology of microalgae mass cultures: Understanding the tools for the next green revolution. Biofuels 2010, 1, 143-162. [CrossRef]

15. Kokkinos, N.; Lazaridou, A.; Stamatis, N.; Orfanidis, S.; Mitropoulos, A.C.; Christoforidis, A.; Nikolaou, N. Biodiesel production from selected microalgae strains and determina tion of its properties and combustion specific characteristics. J. Eng. Sci. Technol. Rev. 2015, 8, 1-6. [CrossRef]

16. Hestekin, J.; Lopez, A.; Clausen, E.; Potts, T. Biobutanol. In Applications of Microbial Engineering, 1st ed.; Gupta, V.K., Schmoll, M., Maki, M., Tuohy, M., Mazutti, M.A., Eds.; CRC Press: Boca Raton, FL, USA, 2013; pp. 450-487.

17. Rakopoulos, D.; Rakopoulos, C.; Giakoumis, E.; Dimaratos, A.; Kyritsis, D. Effects of butanol-diesel fuel blends on the performance and emissions of a high-speed DI diesel engine. Energy Convers. Manag. 2010, 51, 1989-1997. [CrossRef]

18. Dimian, A.C.; Bildea, C.S.; Kiss, A.A. Bioethanol and biobutanol. In Applications in Design and Simulation of Sustainable Chemical Processes; Elsevier: Amsterdam, The Netherlands, 2019; pp. 285-327.

19. Kumbár, V.; Dostál, P. Temperature dependence density and kinematic viscosity of petrol, bioethanol and their blends. Pak. J. Agric. Sci. 2014, 51, 175-179.

20. Yilmaz, N. Temperature-dependent viscosity correlations of vegetable oils and biofuel-diesel mixtures. Biomass Bioenergy 2011, 35, 2936-2938. [CrossRef]

21. Peterka, B.; Pexa, M.; Čedík, J.; Aleš, Z. The influence of biobutanol on performance parameters of mobile generator. Agron. Res. 2016, 14, 167-173. 
22. Rakopoulos, C.D.; Rakopoulos, D.C.; Giakoumis, E.G.; Kyritsis, D.C. The combustion ofn-butanol/diesel fuel blends and its cyclic variability in a direct injection diesel engine. Proc. Inst. Mech. Eng. Part A J. Power Energy 2011, 225, 289-308. [CrossRef]

23. Qi, D.; Lee, C. Combustion and emissions behaviour for ethanol-gasoline-blended fuels in a multipoint electronic fuel injection engine. Int. J. Sustain. Energy 2014, 35, 1-16. [CrossRef]

24. Hönig, V.; Pexa, M.; Mařík, J.; Linhart, Z.; Zeman, P. Biobutanol standardizing waste cooking oil as a biofuel. Pol. J. Environ. Stud. 2017, 26, 69-78. [CrossRef]

25. Kumbár, V.; Polcar, A.; Votava, J. Physical and mechanical properties of bioethanol and gasoline blends. Listy Cukrov. Řepařské 2015, 131, 112-116.

26. Peleg, M. Temperature-viscosity models reassessed. Crit. Rev. Food Sci. Nutr. 2018, 58, 2663-2672. [CrossRef]

27. Peleg, M.; Normand, M.D.; Corradini, M.G. The arrhenius equation revisited. Crit. Rev. Food Sci. Nutr. 2012, 52, 830-851. [CrossRef] [PubMed]

28. Trávníček, P.; Valach, M.; Hlaváčová, Z.; Mareček, J.; Vítěz, T.; Junga, P. Selected physical properties of liquid biofuels. Res. Agric. Eng. 2013, 59, 121-127. [CrossRef]

29. Hlavac, P.; Božiková, M.; Cviklovič, V. Dynamic viscosity and activation energy of wort during fermentation and storing. Acta Technol. Agric. 2016, 19, 6-9.

30. Hlaváčová, Z.; Božiková, M.; Hlaváč, P.; Regrut, T.; Ardonová, V. Selected physical properties of various diesel blends. Int. Agrophys. 2018, 32, 93-100. [CrossRef]

31. Barabás, I. Predicting the temperature dependent density of biodiesel-diesel-bioethanol blends. Fuel 2013, 109, 563-574. [CrossRef]

32. Poling, B.E.; Prausnitz, J.M.; O'Connell, J.P. Properties of Gases and Liquids, 5th ed.; McGraw-Hill Education: New York, NY, USA, 2001; pp. 154-196.

33. Tesfa, B.; Mishra, R.; Gu, F.; Powles, N. Prediction models for density and viscosity of biodiesel and their effects on fuel supply system in CI engines. Renew. Energy 2010, 35, 2752-2760. [CrossRef]

34. Olanrewaju, A.A.; Hasan, S.W.; Abu-Zahra, M.R.M. Rheological and physicochemical characterization of UAE crude oil. Pet. Sci. Technol. 2016, 34, 659-664. [CrossRef]

35. Kumbár, V.; Votava, J. Differences in engine oil degradation in spark-ignition and compres-sion-ignition engine. Eksploat. Niezawodn. Maint. Reliab. 2014, 16, 622-628.

36. Brandão, L.F.P.; Suarez, P.A.Z. Determination of the alternative butanol/gasoline and butanol/diesel fuel blends heats of combustion by a heat-loss compensated semi-microcalorimeter. J. Therm. Anal. Calorim. 2018, 132, 1953-1960. [CrossRef] 